\title{
Two words, one meaning: evidence of automatic co-activation of translation equivalents
}

\author{
Maria Dimitropoulou ${ }^{1,2}{ }^{*}$, Jon Andoni Duñabeitia ${ }^{1}$ and Manuel Carreiras ${ }^{1,3,4}$ \\ 1 Basque Center on Cognition, Brain and Language, Donostia, Spain \\ 2 Departamento de Psicología Cognitiva, Social y Organizacional, Universidad de La Laguna, Tenerife, Spain \\ 3 IKERBASQUE Basque Foundation for Science, Bilbao, Spain \\ ${ }^{4}$ Departamento de Filología Vasca, Universidad del País Vasco/ Euskal Herriko Unibertsitatea, Bilbao, Spain
}

\section{Edited by:}

Clara D. Martin, Universitat Pompeu Fabra, Spain

\section{Reviewed by:}

Jonathan Grainger, Laboratoire de Psychologie Cognitive, CNRS, France Kenneth Forster, University of Arizona, USA

\section{${ }^{*}$ Correspondence:}

Maria Dimitropoulou, Basque Center on Cognition, Brain and Language,

Paseo Mikeletegi 69, 20009-Donostia Spain.

e-mail:m.dimitropoulou@bcbl.eu
Research on the processing of translations offers important insights on how bilinguals negotiate the representation of words from two languages in one mind and one brain. Evidence so far has shown that translation equivalents effectively activate each other as well as their shared concept even when translations lack of any formal overlap (i.e., non-cognates) and even when one of them is presented subliminally, namely under masked priming conditions. In the lexical decision studies testing masked translation priming effects with unbalanced bilinguals a remarkably stable pattern emerges: larger effects in the dominant (L1) to the non-dominant (L2) translation direction, than vice versa. Interestingly, this asymmetry vanishes when simultaneous and balanced bilinguals are tested, suggesting that the linguistic profile of the bilinguals could be determining the pattern of cross-language lexico-semantic activation across the L2 learning trajectory. The present study aims to detect whether $L 2$ proficiency is the critical variable rendering the otherwise asymmetric cross-language activation of translations obtained in the lexical decision task into symmetric. Non-cognate masked translation priming effects were examined with three groups of Greek (L1)-English (L2) unbalanced bilinguals, differing exclusively at their level of $L 2$ proficiency. Although increased $L 2$ proficiency led to improved overall L2 performance, masked translation priming effects were virtually identical across the three groups, yielding in all cases significant but asymmetric effects (i.e., larger effects in the $\mathrm{L} 1 \rightarrow \mathrm{L} 2$ than in the $\mathrm{L} 2 \rightarrow \mathrm{L} 1$ translation direction). These findings show that proficiency does not modulate masked translation priming effects at intermediate levels, and that a native-like level of L2 proficiency is needed for symmetric effects to emerge. They furthermore, pose important constraints on the operation of the mechanisms underlying the development of cross-language lexico-semantic links.

Keywords: bilingualism, masked translation priming, proficiency

\section{INTRODUCTION}

The learning of a non-dominant second language (L2) by associating a newly learnt word to its translation equivalent in the dominant native language (L1) represents the most common L2 teaching strategy (e.g., Jiang and Forster, 2001; Kroll and Tokowicz, 2005; Comesaña et al., 2009). However, as the proficiency level of the bilinguals increases the need to refer to the $\mathrm{L} 1$ to communicate in the L2 decreases (Kroll et al., 2002). In other words, the gradual L2 acquisition leads to gradually enhanced autonomy of this language. This progressive independence of the $\mathrm{L} 2$ could be reflected in the way L2 words are processed and represented in relationship to both their L1 translations and their corresponding conceptual representations. The current study reviews the existing evidence of automatic co-activation of translation equivalents gathered using the masked translation priming paradigm and empirically addresses the issue of whether the level of L2 proficiency affects masked translation priming effects. This way, we aim at testing whether at different stages of the L2 acquisition process, when the representational status of the $\mathrm{L} 2$ with respect to the $\mathrm{L} 1$ differs, the patterns of automatic co-activation of translation equivalents vary.
In order to examine the representational status of translation pairs and the extent to which their conceptual overlap leads to their automatic co-activation, numerous studies have used a version of the masked priming paradigm (Forster and Davis, 1984), the masked translation priming. In this paradigm a pattern mask is first presented for $500 \mathrm{~ms}$ followed by the brief presentation of a lowercase prime $(\sim 50 \mathrm{~ms})$ which can be either the translation or a word of the same language unrelated to the immediately following uppercase target word (e.g., casa-HOUSE vs. rueda-HOUSE, casa, and rueda are the Spanish words for house and wheel). The great advantage of this paradigm lies in the masking of the prime, which makes participants unaware of its presence (see Kinoshita and Lupker, 2003, for review).

\section{MASKED PRIMING EVIDENCE ON TRANSLATION PROCESSING}

Following the masked priming procedure, with some small variations in the sequence and timing of the events, almost 20 studies in the last two decades have reported what has been termed as the masked translation priming effect: faster responses to the targets when they are preceded by their translation than by an unrelated 
word of the non-target language (see Duñabeitia et al., 2010a, for a recent review). This masked translation priming effect has been proposed to result from the automatic activation of the common conceptual node between prime and target and from the existence of strong cross-language interactions at the lexical level (see Forster and Jiang, 2001), although it is also modulated by the sublexical overlap between translations (i.e., larger effects with cognates, e.g., guitar and its Spanish translation guitarra, as compared to non-cognates, e.g., house and its Spanish translation casa; e.g., Gollan et al., 1997; Voga and Grainger, 2007; Davis et al., 2010; Duñabeitia et al., 2010a; but see Kim and Davis, 2003). However, the vast majority of masked translation priming studies has focused on the processing of non-cognates translations, tapping exclusively on lexico-semantic levels of representations due to the lack of any sublexical overlap between them. The essentially semantic origins of the non-cognate masked translation priming effects have been also confirmed in a number of electrophysiological studies reporting more negative-going waveforms for unrelated primes as compared to translation primes in the N400 time-window, reflecting a facilitation of the semantic processing of the targets preceded by their translation primes (Midgley et al., 2009; Duñabeitia et al., 2010a; Hoshino et al., 2010; Schoonbaert et al., 2010).

A remarkable finding in this domain is the so-called non-cognate masked translation priming asymmetry: different magnitude of effects across the two translation directions (i.e., forward, with L1 primes and L2 targets, or backward, with L2 primes and L1 targets) suggesting that fast and automatic lexico-semantic interactions are greatly affected by the readers' knowledge of the language of the input stimuli. The first report of the masked translation priming asymmetry was obtained in the lexical decision task by Gollan et al. (1997), who found large forward and null backward masked translation priming effects. However, asymmetric effects in the opposite direction have been also found in the episodic old-new recognition task (e.g., Jiang and Forster, 2001; Finkbeiner, 2005). Interestingly, this asymmetric representational status of L1 and L2 items is only captured in tasks without an explicit semantic component, whereas when participants are overtly instructed to semantically process the stimuli the effects are comparable across the two translation directions (i.e., semantic categorization task; Grainger and Frenck-Mestre, 1998; Finkbeiner et al., 2004; Wang and Forster, 2010).

While the task-dependency of the masked translation priming asymmetry has implications in understanding the exact nature of the asymmetry(see Jiang and Forster, 2001, for discussion), the extensive use of the lexical decision task in monolingual and bilingual psycholinguistic research and the fact that the masked translation priming asymmetry was first obtained in this task has led the vast majority of non-cognate masked translation priming studies to use this task, with most of them replicating the initially reported asymmetry (i.e., larger effects in the $\mathrm{L} 1 \rightarrow \mathrm{L} 2$ translation direction, than vice versa; see Table 1 for an overview of the lexical decision non-cognate masked translation priming literature). In further detail, out of 16 studies, 13 have found robust masked translation priming effects with L1 primes and L2 targets (i.e., forward translation; a mean effect of $41 \mathrm{~ms}$ across 21 experiments), while only seven studies have found such an effect with L2 primes and L1 targets (i.e., backward translation; a mean advantage of $9 \mathrm{~ms}$ ). In fact, even in the cases where there was a numerical effect in the $\mathrm{L} 2 \rightarrow \mathrm{L} 1$ translation direction, this is usually smaller than in the $\mathrm{L} 1 \rightarrow \mathrm{L} 2$ direction (in 10 out of the 13 studies testing both translation directions) and sometimes non-significant (11 experiments out of 19 testing this translation direction). The same asymmetric pattern reported in the lexical decision latencies has been also confirmed by electrophysiological findings with N400 non-cognate masked translation priming effects being mostly evident in the forward and less in the backward translation direction (but see Duñabeitia et al., 2010b; see also Nakamura et al., 2010, for an fMRI replication).

This asymmetric pattern of masked translation priming effects found in reaction times and neuroimaging studies could seem initially surprising given that one would expect that the effects would be unaffected by the translation direction. However, it becomes much easier to accommodate these findings by considering that all the studies reporting asymmetric masked translation priming effects have tested bilinguals who were clearly less proficient in their L2 than in their L1, namely unbalanced bilinguals (see Table 1 and Duñabeitia et al., 2010b, for a review of the ERP studies). Thus, suggesting that processing differences between words of the dominant and the non-dominant languages would lead to this directional asymmetry. This explanation of the asymmetry would therefore lead to the prediction that when this representational L1-L2 imbalance is attenuated or eliminated, namely with very highly proficient native-like bilinguals or with bilinguals without a clear L1 preference (i.e., balanced), the asymmetry should vanish. In support of this proposal, Basnight-Brown and Altarriba (2007) found symmetric effects with very highly proficient Spanish-English ${ }^{1}$ bilinguals who had undergone a language dominance shift. The fact that they had even reported being more competent in the language they acquired later as compared to their native language could have led to this symmetric pattern of effects. Even stronger evidence in this line, was recently reported by Duñabeitia et al. (2010a) testing balanced Basque-Spanish bilinguals who were constantly exposed to both of their languages. The authors found significant and symmetric bi-directional effects, which were also replicated in an ERP study with bilinguals of the same characteristics (Duñabeitia et al., 2010b). The only evidence so far against a critical involvement of the level of L2 proficiency in the pattern of masked translation priming effects has been reported with a group of low proficient Dutch-French bilinguals yielding significant effects in both translation directions (Duyck and Warlop, 2009).Surprisingly, in spite of their large numerical difference $(22 \mathrm{~ms})$ these effects were not significantly different from each other. Nevertheless, in the light of this unexpected symmetry the authors suggested that a potential lack of statistical power could be leading to these results. In fact, in another study testing two groups of Greek-Spanish bilinguals of a comparable low-level of L2 proficiency (Dimitropoulou et al., 2011a) asymmetric effects, significant only in the L1 $\rightarrow$ L2 translation, were found, fully replicating the previously established asymmetry reported with unbalanced bilinguals. Crucially, the asymmetry persisted even when participants were provided with $50 \mathrm{~ms}$ extra time to process the primes, exactly mimicking the procedure followed

${ }^{1}$ Please note that with the exception of bilinguals without a clear language dominance (i.e., balanced bilinguals), throughout the manuscript the dominant language is presented first and the non-dominant second. 


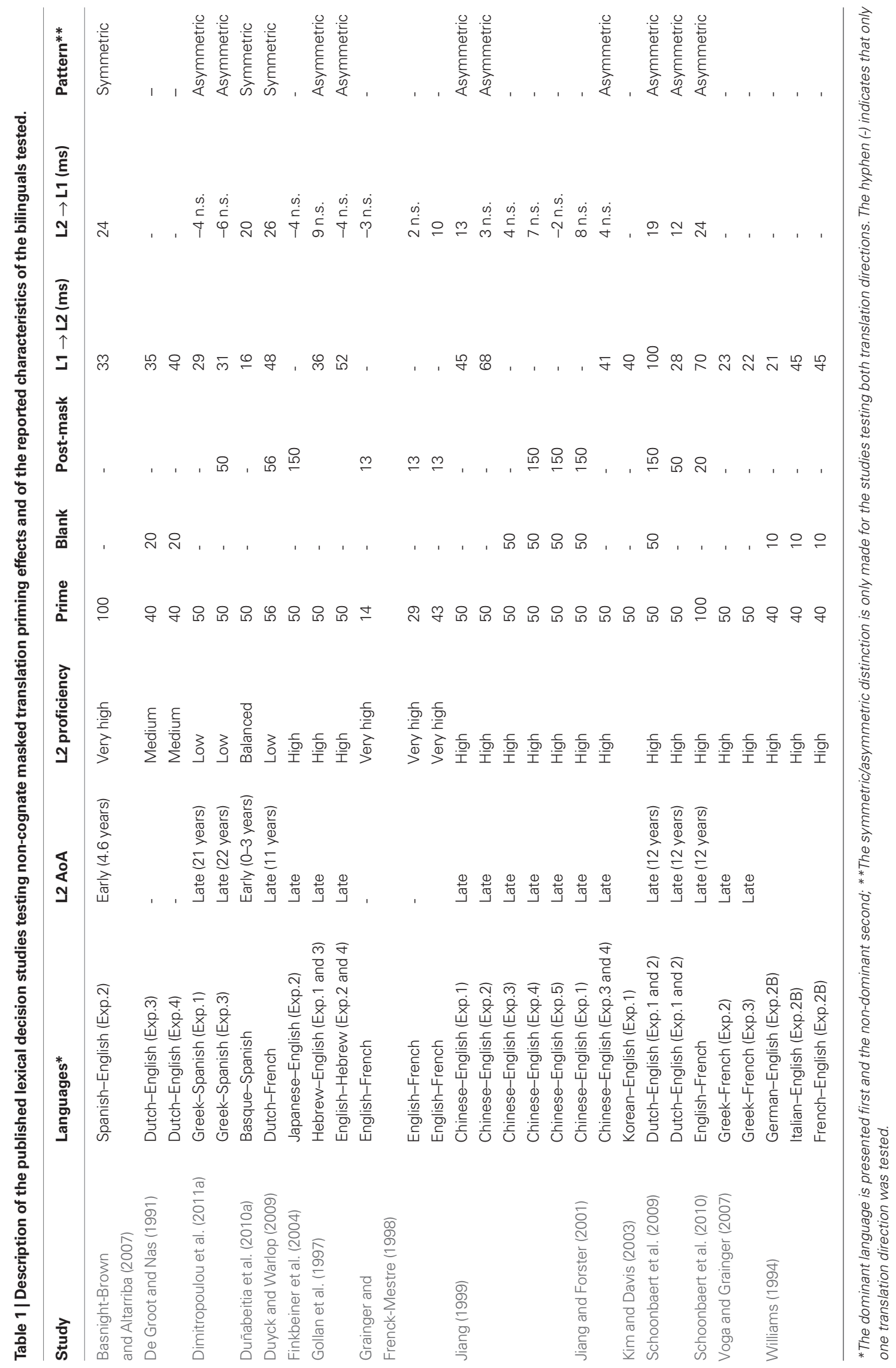


by Duyck and Warlop (2009). In the light of the general pattern of effects obtained across the different studies it becomes feasible to assume that the level of L2 competence is the critical factor driving the pattern of masked translation priming effects.

\section{EFFECTS OF L2 PROFICIENCY ON LEXICO-SEMANTIC PROCESSING}

The assumption that masked translation priming effects could be influenced by the level of L2 proficiency is further supported by evidence pointing to a critical role of this factor in the lexico-semantic processing of L2 and in the extent to which this is comparable to that of the dominant language (e.g., Leonard et al., 2011). Several studies have shown that although less proficient bilinguals can directly access the meaning of L2 words, they perform worse than more proficient bilinguals in tasks requiring the lexico-semantic activation of L2 items (e.g., Chen and Leung, 1989; Chee et al., 2001; Sunderman and Kroll, 2006; see Kroll et al., 2010; Van Heuven and Dijkstra, 2010, for recent reviews). Favreau and Segalowitz (1983) showed that at brief stimulus-onset asynchronies (SOAs) highly proficient bilinguals showed greater semantic priming than less proficient bilinguals when reading in their L2. Using the masked priming paradigm several studies have reported different cross-language associative/ semantic effects with bilinguals of different levels of L2 proficiency. Testing relatively high proficient unbalanced bilinguals Schoonbaert et al. (2009) obtained significant bi-directional effects which were however larger in the L1 $\rightarrow$ L2 priming direction (see also Duyck, 2005). Similar to what has been reported in the non-cognate masked translation priming literature, this directional asymmetry is eliminated with balanced native bilinguals, with bi-directional and symmetric associative/semantic effects emerging (Perea et al., 2008; but see Basnight-Brown and Altarriba, 2007). Even more relevant for the purposes of the present study is the evidence showing different effects at different levels of L2 proficiency in tasks involving the processing of translation equivalents. Kroll et al. (2002) found that unbalanced bilinguals were faster in producing the L1 translation of an L2 word, than vice versa and that this asymmetry was smaller with a more proficient but still unbalanced group (see also Alvarez et al., 2003; Christoffels et al., 2006). In the comprehension domain, it has been shown that the performance of low proficient bilinguals is more sensitive to the resemblance of $\mathrm{L} 2$ words to their $\mathrm{L} 1$ translation and less to their semantic overlap, while the opposite is true for more competent groups of bilinguals and that when processing L2 words the activation of the $\mathrm{L} 1$ translation becomes less pronounced when L2 proficiency increases (e.g., Talamas et al., 1999; Elston-Güttler et al., 2005; Ferré et al., 2006; Sunderman and Kroll, 2006; but see De Groot and Poot, 1997; Thierry and Wu, 2007). To sum up, three relatively consistent findings reported across the bilingual literature are that: (i) early in the L2 acquisition process L2 lexico-semantic access seems to be more effortful than later on, (ii) at this stage the reliance on the activation of the L1 translation equivalent is larger and, (iii) as the L2 proficiency level increases, asymmetries in the processing of L1 and L2 words are attenuated.

\section{THEORETICAL ACCOUNTS OF MENTAL TRANSLATION ACROSS THE L2 PROFICIENCY SPAN}

Accounting for the set of findings pointing to a critical role of L2 proficiency in the representational status of the two languages of bilinguals has been one of the core aims of most models of bilingual lexico-semantic organization (see French and Jacquet, 2004; Grainger et al., 2010; for reviews). Kroll and colleagues developed a theoretical account explicitly designed to account for the processing of translation equivalents at different levels of L2 proficiency during language production: the revised hierarchical model (RHM; e.g., Kroll and Stewart, 1994; Kroll and Tokowicz, 2001, 2005). In its most recent version, the RHM posits that L1 and L2 words are stored in functionally separate lexicons that are linked to a common semantic/conceptual store. Critically, the progressive increase in L2 proficiency is reflected in the strengthening of the links of L2 words to their corresponding concepts and the weakening of their links to their L1 equivalent lexical item. Due to this pattern of lexicosemantic connections, low proficient bilinguals need to activate the L1 translation equivalent to retrieve the corresponding L2 word, while at the same time they are slower at accessing the meaning of L2 words as compared to that of L1 words (see Kroll et al., 2010). As the level of L2 proficiency increases the lexical and semantic connections of L2 words become gradually more comparable to those of L1 words, up to the extent of becoming symmetrical, when bilinguals reach the highest levels of L2 proficiency. With regard to the non-cognate masked translation priming asymmetry Kroll and colleagues proposed that when testing unbalanced bilinguals the semantic activation would be more effective with L1 primes as compared to L2 primes due to the stronger links between L1 words and concepts, hence leading to larger masked translation priming effects (Kroll and de Groot, 1997; Kroll and Tokowicz, 2001). Following the model's central assumption of a progressively more symmetric pattern of L1 and L2 lexico-semantic links as a matter of increased L2 proficiency, the RHM would predict that the masked translation priming asymmetry would be gradually attenuated as the level of L2 competence would increase and eventually eliminated with balanced native-like bilinguals (e.g., Duñabeitia et al., 2010a,b).

Similar predictions regarding the modulation of masked translation priming effects as bilinguals become more proficient in their non-dominant language are also made by the Bilingual Interactive Activation models (BIA and BIA+; e.g., Dijkstra and van Heuven, 1998, 2002; Van Heuven et al., 1998). Masked translation priming effects and their potential modulation by the level of L2 proficiency offer an ideal experimental setting for testing the validity of the BIA models since these models were designed to account for the bilingual visual word recognition findings and they have effectively simulated masked priming effects of cross-language lexico-semantic activation across different levels of L2 proficiency (e.g., Dijkstra and van Heuven, 1998, 2002). The BIA models, which operate based on the same principles as their predecessor, the Interactive Activation model of monolingual visual word recognition (McClelland and Rumelhart, 1981), propose that words of both languages are stored in a single unified lexicon, thus accounting for the cross-language lexico-semantic interactions repeatedly reported. According to the BIA framework, processing asymmetries between L1 and L2 words observed with unbalanced bilinguals are caused by differences in their relative frequency and/or recency of use of L1 and L2 words. For this type of bilingual, L2 words are generally encountered less frequently than L1 words leading to lower resting levels of activation and costlier recognition than for L1 items. However, as the L2 proficiency level increases and bilinguals become more 
exposed to L2 words, their activation thresholds decrease and they become more easily accessed. As a consequence, their recognition becomes more similar to that of L1 words. Within the context of the masked translation priming, this progressive increase in the times a bilingual encounters L2 words is proposed to be reflected in the ease with which the L2 masked primes get activated and activate their corresponding semantic nodes. At higher levels of L2 proficiency, when the L2 primes are the translation equivalents of the targets the pre-activation of the shared meaning would facilitate the processing of the target, thus gradually assimilating the effects obtained with L1 primes and L2 targets.

Very recently, the developmental BIA-d model (Grainger et al., 2010), a new theoretical approach combining some of the critical functional principles of the RHM and the BIA models has been put forward. The BIA-d model was designed to account for the findings revealing changes in L2 lexico-semantic access and L1-L2 interactions throughout the L2 proficiency span. In this framework, initially the newly learnt L2 words are connected via excitatory connections to their L1 translation as well as to their corresponding meaning. These connections are strengthened with increased exposure via Hebbian learning mechanisms, based on the structure and premises of the RHM's developmental account. However, as the L2 proficiency increases and bilinguals reach "a magic moment" in the $\mathrm{L} 2$ acquisition, L2 words become integrated into the L1 lexicon and their recognition proceeds in the frequency-dependent way proposed by the BIA models. The BIA-d posits that at this point the strength of the connections between translation equivalents starts to decrease and the top-down inhibitory control of language activation becomes more effective, thus leading to a more autonomous L2 processing. With regard to the non-cognate masked translation priming effects, the BIA-d model proposes that they reflect ease of direct semantic access of the test items, hence fore explaining the asymmetries observed in unbalanced bilinguals in a way similar to that of the RHM. Accordingly, since throughout the proficiency continuum the excitatory connections of L2 words to their meaning become gradually stronger, thus more comparable to those of L1 words, the BIA-d would predict that as L2 proficiency increases, the masked translation priming asymmetry should be gradually attenuated.

\section{MASKED TRANSLATION PRIMING AND L2 PROFICIENCY}

As can be appreciated, in line with previous evidence and according the predictions offered by some of the most cited bilingual models, the bilinguals' level of L2 proficiency would be expected to modulate non-cognate masked translation priming effects. Nevertheless, this has not been yet examined. A potential reason for this could be that most studies have opted for testing relatively high proficient unbalanced bilinguals with a college-level knowledge of their L2 to partly ensure the effective processing of L2 items. Critically, even when considering the small number of studies intentionally focusing on specific levels of L2 proficiency (low or native-like) to extract the pattern of masked translation priming effects obtained across different levels of L2 proficiency, the existence of a number of issues make it hard to draw reliable cross-study conclusions. The most important limitation involves the diverse and sometimes underspecified linguistic history of the bilinguals tested. This results partly from the exclusive use of either objective or subjective measures of L2 proficiency by some authors (e.g., Jiang, 1999; Jiang and Forster, 2001; Duyck and Warlop, 2009; Schoonbaert et al., 2009) and from the scarce descriptions of the linguistic history of the bilinguals (e.g., Grainger and Frenck-Mestre, 1998; Kim and Davis, 2003). These rather rough descriptions reveal that even when the bilinguals tested had indeed a uniform level of L2 proficiency, their age of L2 acquisition or the context in which L2 was acquired were underspecified. On top of these potentially confounded variables, the great variability in the sizes of the bilingual samples tested (ranging from 3 to 52) as well as in the number of experimental items presented (ranging from 9 to 60 items per priming condition) could be influencing the pattern of effects obtained due to statistical power differences. Finally, only a small number of studies have opted for testing twice the same bilinguals (e.g., Duyck and Warlop, 2009; Duñabeitia et al., 2010a; Dimitropoulou et al., 2011a). The between subject designs add a considerable amount of variance in the response latencies which could be further influencing the pattern of the effects obtained across the two translation directions.

The second crucial limitation in establishing the pattern of masked translation priming effects at different levels of L2 proficiency is the different language combinations examined each time. As shown in Table 1, a large number of studies have used combinations of Romance languages (e.g., Spanish-English, Dutch-English, Dutch-French, etc.) with almost completely overlapping graphemes and phonemes as well as partly overlapping lexicons (i.e., large number of cognates). Two studies have combined partly overlapping scripts (Greek and Roman) while others have used languages involving completely distinct alphabets (Hebrew and Roman) or even different writing systems (logographic and alphabetic). The potential influence of the script and language combinations used in the effects obtained across the different lexical decision noncognate masked translation priming studies can be appreciated in the effects reported so far in the L $2 \rightarrow \mathrm{L} 1$ direction. Critically, all the studies that have shown significant L2 $\rightarrow$ L1 masked translation priming effects have examined languages with a common alphabet. This seems to be somewhat unexpected since the script change present in the cross-language priming conditions of cross-script studies could be thought to facilitate the activation of the nontarget language by providing a low-level visual cue of its presence in the task. Furthermore, although testing languages with a common script mostly yields to significant translation effects, the SpanishEnglish language combination is surprisingly unique since it has only led to null non-cognate masked translation priming effects (e.g., Sánchez-Casas et al., 1992; Davis et al., 2010), though yielding to significant effects with cognates or even with non-cognates when either Spanish or English are combined with other languages (e.g., Schoonbaert et al., 2009; Duñabeitia et al., 2010a). Due to these inconsistencies, whether examining same or different scripts modulates the effects is still an issue under discussion (see Gollan et al., 1997; Hoshino et al., 2010).

Finally, the masked priming methodology used each time could have been also affecting the effects caused by the level of L2 proficiency of the bilinguals. It is noteworthy that significant masked translation priming L2 $\rightarrow$ L1 effects have mostly emerged in studies using SOAs longer than $50 \mathrm{~ms}$ (see Table 1). Schoonbaert et al. (2010) have recently obtained significant bi-directional behavioral and N400 effects with high proficient unbalanced bilinguals by 
presenting the prime for $100 \mathrm{~ms}$ (see also Basnight-Brown and Altarriba, 2007). In the light of their results the authors concluded that "increasing participants' proficiency in L2 or increasing prime-target SOA can be thought of as having the same influence on the amount of processing of briefly presented L2 prime words" ( $\mathrm{p}$. $6)$. However, two studies have tested and rejected the hypothesis that having extra time for processing the L 2 prime by including a blank or a post-mask facilitates the appearance of the otherwise elusive backward masked translation priming effect (Jiang, 1999; Dimitropoulou et al., 2011a). This idea is further supported by the appearance of significant within-language L2 repetition priming effects and of significant backward masked translation priming effects in tasks other than the lexical decision (e.g., Gollan et al., 1997; Finkbeiner et al., 2004).

\section{THE PRESENT STUDY}

In order to empirically address the issue of whether L2 proficiency modulates non-cognate masked translation priming effects we conducted three lexical decision experiments, carefully designed to overcome the limitations previously enumerated. Throughout this series of experiments all the variables proposed to influence non-cognate masked translation priming effects were kept constant and we exclusively manipulated the level of L2 proficiency of the participants. In further detail, after a thorough selection process (see Participant Selection) 108 Greek-English unbalanced bilinguals were assigned to one of three proficiency groups: a relatively low, a medium, and a relatively high proficiency group. Our biggest effort was placed in establishing a clear L2 proficiency distinction across the three groups, based on both subjective and objective measures, and in ensuring that the L2 history of the three groups was otherwise identical. The L2 proficiency manipulation was focused on unbalanced bilingualism since the evidence of symmetric masked translation priming effects across the two translation directions with balanced bilinguals has been confirmed both at the behavioral and at the electrophysiological level (Duñabeitia et al., 2010a,b). To examine the pattern of masked translation priming effects emerging across both translation directions as well as the relationship between them (i.e., asymmetry) while eliminating any between subject variability, each group of bilinguals was tested twice using the exact same large sets of English and Greek materials in two separate experimental sessions. The critical translation pairs used to test both translation directions were frequent one-to-one non-cognate Greek-English translations (e.g., ribbon and its Greek translation $\kappa о \rho \delta \varepsilon \lambda \alpha$ ), thus ensuring that even the low proficient bilinguals would be familiar with the English items. Finally, to further refine the experimental design, for each target language we added a within-language repetition priming condition along with its corresponding within-language control (i.e., identity priming effect, e.g., ribbon-RIBBON vs. desire-RIBBON; e.g., Forster and Davis, 1984; Perea and Rosa, 2000). The use of a within-language full priming condition against which cross-language effects can be compared provides valuable insights into the representational relationship of L1 and L2 words (see Altarriba and Basnight-Brown, 2007). This is more so when testing low proficient bilinguals, since obtaining significant L2 identity priming effects certifies the effective lexical activation of the less frequently encountered L2 words (see also Dimitropoulou et al., 2011a; Gollan et al., 1997; Jiang, 1999; Midgley et al., 2009; for the same $2 \times 2$ design applied in the study of masked translation priming effects).

Overall, we expected to observe a gradually improved performance in English (L2) as a matter of increased proficiency, with progressively shorter latencies and fewer errors from low to medium and to high proficient bilinguals (see De Groot and Poot, 1997). With regard to the masked identity priming effects we expected to obtain significant effects (i.e., shorter latencies for targets primed by their exact repetition than for targets primed by unrelated words of the same language) of comparable magnitude in L1 and in L2 across the three L2 proficiency levels (e.g., Gollan et al., 1997; Dimitropoulou et al., 2011a). Furthermore, considering previous L2 masked priming studies, showing invariant morphological or form priming effects across different levels of proficiency, we did not predict any modulation in the size of the L2 masked identity priming effect across the three groups of bilinguals (see also Duyck et al., 2004; Diependaele et al., 2011; Dimitropoulou et al., 2011b).

Regarding the effects of major interest, the non-cognate masked translation priming effects, we expected to obtain significant forward masked translation priming effects for the three proficiency groups (Experiments 1a, 2a, and 3a), as has been typically the case in the lexical decision masked translation priming literature irrespectively of the level of L2 proficiency of the bilinguals tested (see Table 1, for review). Predictions on whether or not we would also obtain an effect in the opposite translation direction are less clear-cut given the inconsistent previous evidence (see above). Following different rationales, the RHM and the BIA models would predict that such an effect could potentially exist at high levels of L2 proficiency, when the processing of L2 words is more comparable to that of L1 words (see Dijkstra, 2007). If the models' predictions regarding the appearance of the L2 $\rightarrow$ L1 effect at high L2 proficiency levels are confirmed and there is indeed such an effect with the high proficiency group (Experiment 3b), then it could also be expected that for this group this effect could be of comparable magnitude to that of the L1 $\rightarrow \mathrm{L} 2$ masked translation priming effect. If, in contrast to the predictions of the RHM and the BIA models, the level of L2 proficiency of an unbalanced bilingual does not affect the L $2 \rightarrow \mathrm{L} 1$ masked translation priming effect, then asymmetric effects across the two translation directions (i.e., larger effects in forward as compared to backward translation) should be expected for the three proficiency groups.

Finally, the inclusion of equal amount of primes belonging to the target and non-target languages preceding the English (L2) and the Greek (L1) targets as well as the substantial statistical power of our design offer a great opportunity to investigate an effect widely neglected in the behavioral masked priming literature: the masked priming code-switching effect. Code-switching costs have been manifested mostly in word production but also in some recent ERP masked priming reading studies as costlier processing of pictures or words preceded by an item of the non-target language as compared to when they were preceded by items of the same language (e.g., Costa et al., 2006; Chauncey et al., 2008, for review). Out of these studies, the ones testing unbalanced bilinguals have reported a dependence of the code-switching effects on the direction of the code-switch (larger cost from L2 $\rightarrow$ L1, than vice versa), while those testing balanced bilinguals have reported symmetric effects (e.g., Costa 
et al., 2006; Duñabeitia et al., 2010b). However, the only behavioral masked priming studies examining code-switching costs reported symmetric effects even though one tested low proficient unbalanced and the other native-like balanced bilinguals (Perea et al., 2008; Dimitropoulou et al., 2011a). Taking into account these previous behavioral masked priming reports of code-switching effect, we expected to obtain symmetric effects across the two directions of language switch for the three groups of bilinguals tested.

\section{EXPERIMENTS \\ METHOD \\ Participant selection}

To ensure the correct assignment of each participant to his/her corresponding L2 proficiency level as well as the homogeneity of each of the groups to be tested, we opted for assessing the L2 proficiency with both objective and subjective measures. In order to obtain an objective measurement of their proficiency, all the native Greeks comprising the three groups were English learners of different levels at the British Council in Athens. This way apart from making sure that all the bilinguals were exposed to the same type of English input, we were able to identify three distinct levels of English proficiency based on the placement of the bilinguals in three different English courses according to the British Council standards: relatively low, medium, and high proficiency groups. This grouping was made based on thorough spoken and written entry tests as well as on the participants' academic progress in the British Council. The entry tests were administered upon students' first registration and consisted of a written (vocabulary, grammar, and comprehension subtests) and a spoken part. The spoken part of the test was a brief interview during which each student was evaluated on his/her communication skills in English through their answers on a series of open questions. Based on these measures the British Council teaching team indicated that the most clear-cut proficiency distinction was found across the students who were in the process of undertaking one of the three available ESOL Examinations supervised by the University of Cambridge: the First Certificate in English (FCE), the Certificate of Advanced English (CAE), and the Certificate of Proficiency in English (CPE). Once the groups had been identified following the British Council standards, the subjective criterion was applied. The prospective participants answered a number of questions regarding their linguistic and educational background and gave their self-ratings on different measures of proficiency in English by completing a Greek version of the Language Experience and Proficiency Questionnaire (LEAP-Q; Marian et al., 2007). This questionnaire confirmed that all the participants had only lived in Greece, that English was their second language both in terms of proficiency and in order of acquisition and that they were exposed to it only within the context of the British Council. The three proficiency groups were furthermore matched in a number of different variables (mean age of acquisition, age of first exposure to print, chronological age; see Table 2 for a detailed description of the three groups of bilinguals).

\section{Materials}

Exactly the same experimental materials were used in the three experiments (1-3). For sub-experiments $1 \mathrm{a}, 2 \mathrm{a}$, and 3 a we selected 232 English (L2) as word targets (e.g., RIBBON) from the CELEX
Table 2 | Characteristics of the three groups who participated in the experiments and their mean level of English (L2) proficiency as calculated by their self-ratings (Language Experience and Proficiency Questionnaire, LEAP-O) and by the British Council entry tests.

\begin{tabular}{|c|c|c|c|}
\hline \multirow[t]{2}{*}{ Variables controlled (all $p s>0.20$ ) } & \multicolumn{3}{|c|}{ Proficiency level } \\
\hline & Low & Medium & High \\
\hline Age & $22.0(8.6)$ & $24.0(8.1)$ & $24.3(5.3$ \\
\hline Age of first exposure to English & $7.7(2.0)$ & $7.6(2.6)$ & $7.1(2.2)$ \\
\hline Age of first exposure to English reading & $8.8(1.9)$ & $8.6(2.4)$ & $8.6(2.3)$ \\
\hline \multicolumn{4}{|l|}{ PROFICIENCY PLACEMENT CRITERIA } \\
\hline \multicolumn{4}{|l|}{ British Council measures } \\
\hline Cambridge ESOL level & CPE & CAE & FCE \\
\hline Spoken entry test performance* & $5-6$ & $7-8$ & 9 \\
\hline \multicolumn{4}{|l|}{ Self-ratings (all ps $<0.01$ ) } \\
\hline Speaking** & $5.4(1.0)$ & $6.8(1.2)$ & $7.6(1.3)$ \\
\hline Reading** & $6.3(1.6)$ & $7.4(1.0)$ & $8.5(1.0)$ \\
\hline Listening** & $5.8(1.8)$ & $7.4(1.2)$ & $8.2(1.2)$ \\
\hline Overall proficiency** & $5.8(1.4)$ & $6.8(1.0)$ & $7.6(0.9)$ \\
\hline Hours of exposure/week & 8.4 & 13.7 & 19.2 \\
\hline
\end{tabular}

${ }^{* 1}$ = no verbal communication possible, $9=$ complete, fluent, effective communication; * $0=$ low proficiency, $10=$ high proficiency. SD are provided within parentheses.

database (Baayen et al., 1995). These targets were preceded by primes that were: (i) their exact repetition (e.g., ribbon-RIBBON), (ii) an English unrelated word (e.g., desire-RIBBON), (iii) their non-

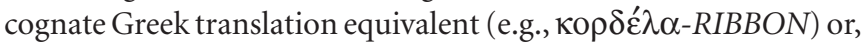

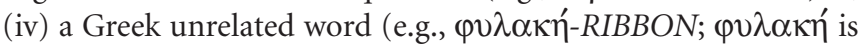
the Greek word for prison). All the words used throughout the study were nouns or adjectives. All the conditions were matched in mean frequency per million and length. All the Greek words were taken from the GreekLex database (Ktori et al., 2008). The selected English-Greek non-cognate pairs were indicated to be the predominant translations of each other by two Greek external judges with a native-like level of competence in English (see Table 3 for a full description of the materials). For the purposes of the lexical decision an additional set of 232 pronounceable non-words was created by replacing two of the target words' letters (e.g., GOMY). In order to have the exact same amount of English and Greek primes throughout the experiment, the non-words were preceded half by Greek and half by English prime words, matched in length and frequency to the primes of the word targets (mean frequency: 97 appearances/million, mean length: 6.2 letters).

In Experiments $1 \mathrm{~b}, 2 \mathrm{~b}$, and $3 \mathrm{~b}$ we used as the critical non-cognate translation pairs the same ones as in Experiments 1a-3a, but this time the Greek primes of the translation condition served as targets and the English targets as translation primes. Just as in Experiments 1a-3a with the English targets, the Greek target words were pre-

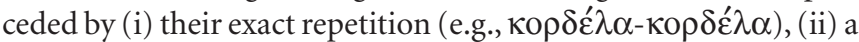

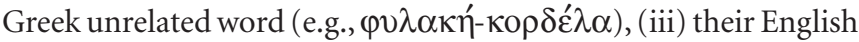

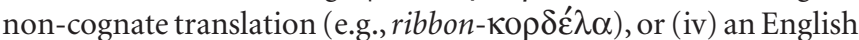

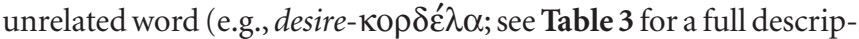
tion of the word materials). 232 pronounceable non-words were created by replacing two of the targets' letters (e.g., $\Xi \mathbf{A} \mathbf{\Lambda} \mathbf{I})$. These 
Table 3 | Characteristics of the word materials used in the experiments.

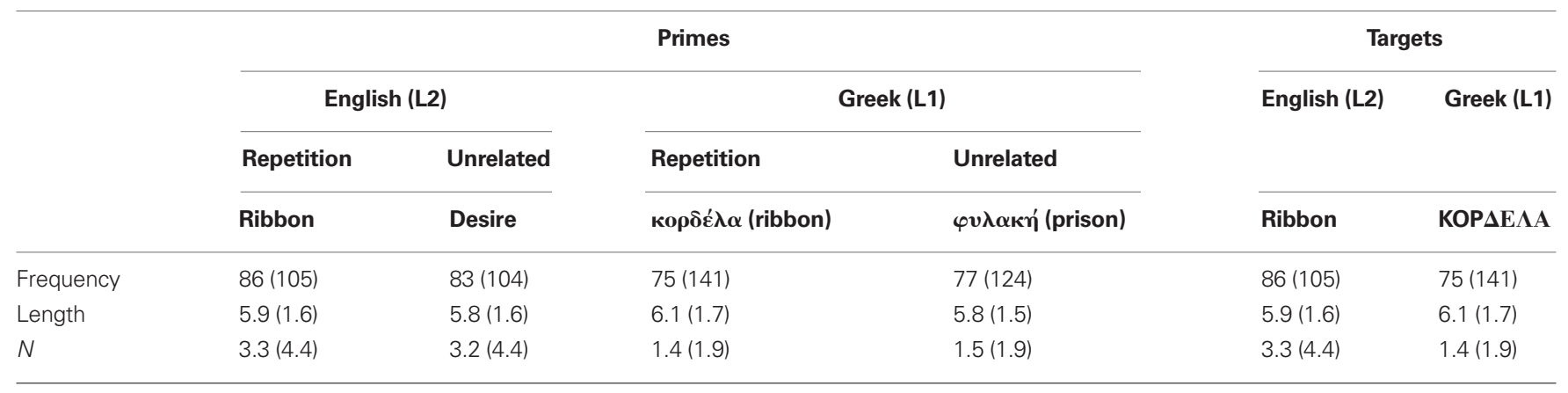

Number of orthographic neighbors (Coltheart et al., 1977). The English N values were taken from N-Watch (Davis, 2005). SD are given within parentheses.

non-words were primed by the same Greek and English words that preceded the non-word targets in Experiments 1-3a (see Altarriba and Basnight-Brown, 2007).

For each sub-experiment four lists of materials were created so that each target appeared only once in each list and each time in a different priming condition. In each of the lists there were 58 experimental items per condition. List assignment was counterbalanced across participants.

\section{Procedure}

All the participants completed the task in English (Experiments $1 \mathrm{a}-3 \mathrm{a})$ and in Greek (Experiments 1b-3b) in two experimental sessions. The sessions took place in two different days with at least a 3-day lag between them and their order was counterbalanced across the participants. The experiments were run using DMDX (Forster and Forster, 2003). Each trial started with the presentation of a forward mask (e.g., \#\#\#\#\#) for $500 \mathrm{~ms}$, followed by the presentation of a lowercase prime for $50 \mathrm{~ms}$ (three cycles; each corresponding to $16.6 \mathrm{~ms}$ on a CRT monitor). Finally, the target string was presented in uppercase, for a maximum of $2500 \mathrm{~ms}$. All the stimuli were presented centered. Participants were asked to indicate as fast and accurately as possible through a keyboard button press, whether the target string was or not a legitimate English (Experiments 1a-3a) or a legitimate Greek word (Experiments 1b-3b). They were not informed of the presence of the primes, and none of them reported conscious knowledge of their existence after completing the experiments. The order of trial presentation was randomized across participants. Prior to the 464 experimental trials each participant was presented with six word and six non-word practice trials. All the interactions with the participants and the experimental instructions were in the language each participant was performing the task in. Each experimental session lasted approximately $20 \mathrm{~min}$.

\section{DATA ANALYSES}

In order to identify the effects produced by each of the three bilingual groups across each translation direction and following previous masked translation priming studies that have used the same design (e.g., Gollan et al., 1997; Dimitropoulou et al., 2011a), ANOVAs based on participant and item response latencies and error percentages were conducted for each group and for each target language. These ANOVAs were based on a 2 (Prime language: English, Greek $) \times 2$ (Relatedness: Repetition, Unrelated $) \times 4$ (List: List 1, 2,
3, 4) design. The factor List was included as a dummy variable (Pollatsek and Well, 1995). This design led to 12 separate sets of ANOVAs for the reaction times and for the error rates too: one for each of the three bilingual groups (low, medium, high proficiency; Experiments 1-3), one for each of the two translation directions $(\mathrm{L} 1 \rightarrow \mathrm{L} 2$ and $\mathrm{L} 2 \rightarrow \mathrm{L} 1)$ and one for participant and item analyses. See Tables 3-5 for mean reaction times, error rates, and priming effects obtained in the different priming conditions throughout Experiments 1-3.

\section{EXPERIMENT 1: LOW PROFICIENCY GROUP Participants}

Thirty-six native Greeks, students of the British Council who were in the process of undertaking the Cambridge exam of the FCE completed this experiment. According to the University of Cambridge standards English learners in preparation for this examination should be able to understand relatively complex pieces of writing and conversations on a variety of topics and to express their opinion. Based on their performance on the spoken part of the British Council entry tests, participants were able to produce longer sentences using simple grammatical structures in English but their communication was slow and occasionally hesitant and they were not yet able to spontaneously initiate a conversation. In overall, participants rated their English proficiency with a 5.8 on a 1-to-10 scale (10 representing the highest level of proficiency; see Table 2 for further information). Note that in both previous masked translation priming studies testing low proficient bilinguals, participants' ratings of their overall proficiency were also in the same range (Duyck and Warlop, 2009; Dimitropoulou et al., 2011a). Each participant completed the task with both English and Greek targets (sub-experiments 1a and $1 \mathrm{~b}$ ).

\section{RESULTS AND DISCUSSION English (L2) targets}

ANOVAs on the reaction times showed a significant main effect of Prime language: participants responded faster $(18 \mathrm{~ms})$ to targets preceded by English repetition and unrelated primes compared to targets preceded by Greek repetition and unrelated primes [a code-switching cost: $F 1(1,32)=26.79, \mathrm{MSE}=434, p<0.001$; $F 2(1,227)=11.56, \mathrm{MSE}=7818, p<0.01]$. Moreover, the main effect of Relatedness was also significant: participants responded faster $(48 \mathrm{~ms})$ to targets preceded by repetition primes (English 
and Greek) than to targets preceded by English and Greek unrelated primes $[F 1(1,32)=166.58$, MSE $=489, p<0.001$; $F 2(1,227)=126.28, \mathrm{MSE}=4835, p<0.001]$. Importantly, the interaction between the two factors was also significant, indicating that the Identity priming effect was significantly larger than the Translation priming effect [a 34-ms difference; $F 1(1,32)=23.45$, $\mathrm{MSE}=450, p<0.001 ; F 2(1,227)=13.05, \mathrm{MSE}=4003, p<0.001]$. The pairwise comparisons showed that responses to targets preceded by their exact English repetition were faster (65 ms faster) than responses to targets preceded by unrelated English words [Identity priming effect: $F 1(1,32)=177.86, \mathrm{MSE}=436, p<0.001$; $F 2(1,227)=127.70, \mathrm{MSE}=3993, p<0.001]$. Similarly, responses to targets preceded by their Greek non-cognate translations were faster ( $31 \mathrm{~ms}$ faster) than responses to targets preceded by unrelated Greek words [Translation priming effect: $F 1(1,32)=33.15$, $\mathrm{MSE}=503, p<0.001 ; F 2(1,227)=8.81, \mathrm{MSE}=3601, p<0.01]$.

ANOVAs on the error rates showed a main effect of Relatedness: targets were responded to more accurately (3.3\% less errors) when they were primed by repetition primes (English and Greek) as compared to when they were primed by unrelated English and Greek primes $[F 1(1,32)=37.82, \mathrm{MSE}=10, p<0.001 ; F 2(1,228)=31.04$, $\mathrm{MSE}=86, p<0.001]$. The rest of the effects did not reach significance (all ps $>0.15)$.

\section{GREEK (L1) TARGETS}

ANOVAs on the reaction times showed a main effect of Prime Language, reflecting a $15-\mathrm{ms}$ cost in the trials involving a primetarget language change $[F 1(1,32)=20.11, \mathrm{MSE}=396, p<0.001$; $F 2(1,228)=10.51, \mathrm{MSE}=5702, p<0.01]$. There was also a main effect of Relatedness, with repetition primes (Greek and English) leading to faster lexical decision times ( $36 \mathrm{~ms}$ faster) than unrelated primes [ of both languages; $F 1(1,32)=129.53, \mathrm{MSE}=453, p<0.001$; $F 2(1,228)=13.49, p<0.001]$. Critically, the interaction between the two factors was also significant showing that the Identity and the Translation priming effects differed in magnitude $[F 1(1,32)=27.63$, $\mathrm{MSE}=412, p<0.001 ; F 2(1,228)=36,48, \mathrm{MSE}=2883, p<0.001]$. The pairwise comparisons reveled that, despite their numerical difference ( $43 \mathrm{~ms}$ ) both the Identity and the Translation priming effects were significant [Identity priming effect: $57 \mathrm{~ms}, F 1(1,32)=153.27$,
$\mathrm{MSE}=376, p<0.001 ; F 2(1,228)=115.07, \mathrm{MSE}=3263, p<0.001 ;$ Translation priming effect: $14 \mathrm{~ms}, F 1(1,32)=20.40, \mathrm{MSE}=189$, $p<0.001 ; F 2(1,228)=8.81, \mathrm{MSE}=3601, p<0.01]$.

The error rate analysis revealed a significant main effect of Prime Language: targets were responded to $1.2 \%$ more accurately when preceded by Greek primes than by English primes $[F 1(1,32)=7.29, \mathrm{MSE}=7, p<0.05 ; F 2(1,228)=3.97, \mathrm{MSE}=86$, $p<0.05]$. Furthermore, there was a main effect of Relatedness: participants made $1.5 \%$ less errors to targets preceded by their repetitions (either Greek or English) compared to targets preceded by unrelated primes $[F 1(1,32)=7.23, \mathrm{MSE}=12, p<0.05$; $F 2(1,228)=7.58, \mathrm{MSE}=81, p<0.01]$. The rest of the effects were not significant (all $p s>0.55$; see Table 4 ).

The main finding of Experiment 1 was an asymmetric pattern of non-cognate masked translation priming effects obtained with relatively low proficient Greek-English bilinguals: significant masked translation priming effects were found in both translation directions with a larger effect emerging in the forward translation (31 vs. $14 \mathrm{~ms}$ in the backward translation). This asymmetry is in line with the vast majority of previous studies testing unbalanced bilinguals (see Table 1). In contrast to this pattern of translation effects, the code-switching costs observed were unaffected by the prime-target language (i.e., L1 $\rightarrow$ L2 and L2 $\rightarrow$ L1 switches lead to symmetric significant costs of 18 and $14 \mathrm{~ms}$, respectively). Similarly, the masked identity priming effects found with Greek (57 ms) and English targets (65 ms) were also comparable in magnitude.

The overall pattern of the different masked priming effects was further confirmed by a set of post hoc combined analyses of the lexical decision latencies of Experiments $1 \mathrm{a}$ and $1 \mathrm{~b}$ in which Target language was included as a factor. With regard to the two translation priming effects these analyses confirmed that the 31-ms forward masked translation priming effect was significantly larger than the 14-ms backward translation as indicated by the significant interaction of Target language and Relatedness found for the between language priming conditions (translation and unrelated) Target language and Relatedness interacted with each other, $[F 1(1,32)=6.27$, $\mathrm{MSE}=359, p<0.05 ; \mathrm{F} 2(1,228)=5.73, \mathrm{MSE}=3997, p<0.05]$. In contrast, this interaction was not significant when analyzing conjointly the within-language conditions (repetition and unrelated)

Table 4 | Mean lexical decision times (in ms, RT) and error rates (\%E) for word targets in sub-experiments $1 \mathrm{a}$ and $1 \mathrm{~b}$.

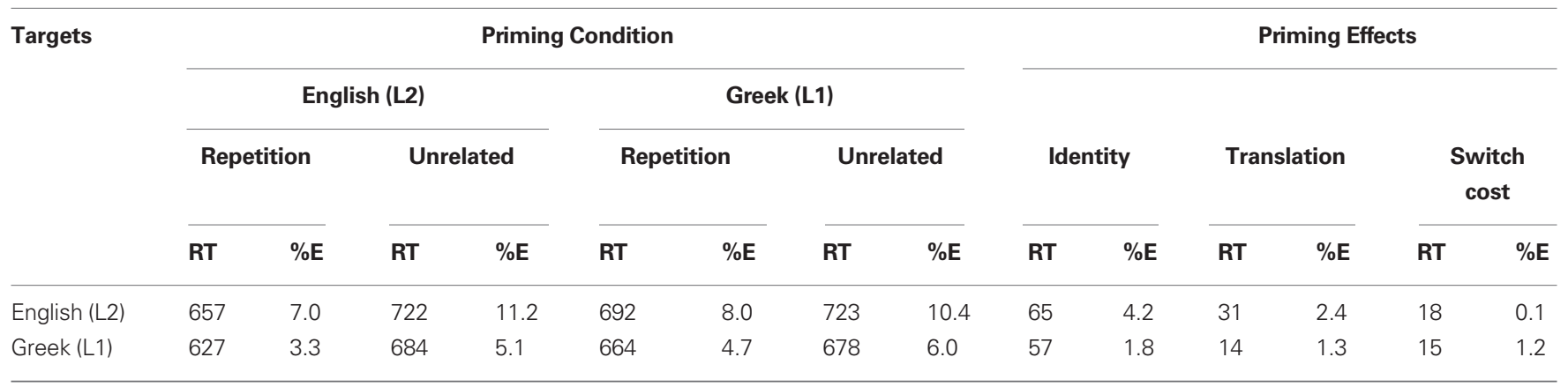

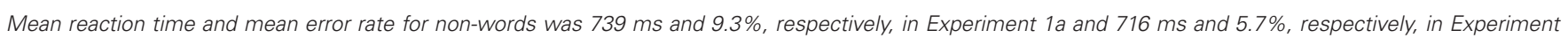

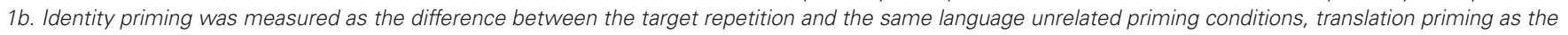

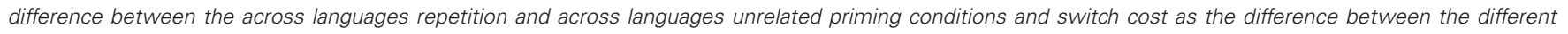
language and the same language priming conditions. 
across Experiments 1a,b (both $p s>0.19$ ) indicating that the 8-ms difference in the within-language repetition priming effects was negligible. Finally, the lack of a directional asymmetry for the two code-switching effects found was confirmed by the absence of an interaction between Target language and Prime language (target, non-target; both $p s>0.55$ ).

In Experiment 2, we used the same materials and procedure to examine the masked translation priming with another group of unbalanced Greek-English bilinguals taken from the same English learning context, who had a higher level of English proficiency, which we termed as medium proficiency. In the light of the results obtained with the low proficient group we expected to find an asymmetric pattern of masked translation priming effects in the presence of significant effects in both translation directions.

\section{EXPERIMENT 2: MEDIUM PROFICIENCY GROUP Participants}

Thirty-six native Greek students of the British Council who were in the process of undertaking the exam of the Certificate in Advanced English completed this experiment. According to the standards of the University of Cambridge, English learners at this level should be able to follow an English academic course and to communicate effectively in English. Based on the spoken entry test measures, which were collected by the British Council, participants were able to spontaneously initiate a conversation in English and maintain interactions at a relatively normal speed on a wide range of topics. They had still some difficulties in pronunciation and in producing complex grammatical constructions and needed occasional assistance from the interlocutor. Participants rated their overall English proficiency with a mean of 6.8 (out of 10; see Table 2).

\section{RESULTS AND DISCUSSION English (L2) targets}

ANOVAs on the target word latencies revealed a significant main effect of Prime language, with English targets preceded by same language repetition or unrelated primes being responded to $20 \mathrm{~ms}$ faster than when preceded by repetition on unrelated Greek primes $[F 1(1,32)=27.79, \mathrm{MSE}=535, p<0.001 ; F 2(1,227)=8.67$, $\mathrm{MSE}=9327, p<0.001]$. The main effect of Relatedness was also significant. Targets were responded to $45 \mathrm{~ms}$ faster when primed by their repetitions (both identity and translation) than when they were preceded by unrelated English or Greek words $[F 1(1,32)=87.24$, $\mathrm{MSE}=847, p<0.001 ; F 2(1,227)=114.17, \mathrm{MSE}=4585, p<0.001]$. Furthermore, these two factors significantly interacted with each other $[F 1(1,32)=19.53, \mathrm{MSE}=539, p<0.001 ; F 2(1,227)=21.66$, $\mathrm{MSE}=4119, p<0.001]$. Planned pairwise comparisons revealed a 63-ms identity priming effect $[F 1(1,32)=204.40, \mathrm{MSE}=343$, $p<0.001 ; F 2(1,227)=126.94, \mathrm{MSE}=4116, p<0.001]$ as well as a 28 -ms translation priming effect $[F 1(1,32)=13.73, \mathrm{MSE}=1043$, $p<0.001 ; F 2(1,228)=18.40, \mathrm{MSE}=4644, p<0.001]$. However, the translation priming effect was significantly smaller than the identity priming effect, as indicated by the significant Prime language by Relatedness interaction previously described.

ANOVAs on the error rates on the word targets showed a significant main effect of Relatedness. Participants made 2.7\% less errors to targets preceded by their repetitions (identity and translation) compared to when they were preceded by unrelated
English or Greek primes $[F 1(1,32)=18.78, \mathrm{MSE}=14, p<0.001$; $F 2(1,228)=23.50, \mathrm{MSE}=67, p<0.001]$. The rest of the effects did not reach significance (all $p s>0.25$ ).

\section{Greek (L1) targets}

ANOVAs on the reaction times showed a main effect of Prime language. Greek targets preceded by Greek primes were responded to faster (20 ms faster) than targets preceded by English primes $[F 1(1,32)=41.67, \mathrm{MSE}=346, p<0.001 ; F 2(1,228)=23.53$, $\mathrm{MSE}=3215, p<0.001]$. The main effect of Relatedness was also significant, with targets preceded by their within and cross-language repetitions being responded to $39 \mathrm{~ms}$ faster than when preceded by unrelated Greek and English primes $[F 1=190.56, \mathrm{MSE}=293$, $p<0.001 ; F 2(1,228)=164.85, \mathrm{MSE}=2268, p<0.001]$. Finally, there was a significant interaction between Prime language and Relatedness suggesting that the magnitude of the identity priming effect exceeded that of the translation priming effect [66 and $14 \mathrm{~ms}$, respectively; $F 1(1,32)=122.84, \mathrm{MSE}=201, p<0.001$; $F 2(1,228)=91.97, \mathrm{MSE}=2121, p<0.001]$. The subsequent pairwise comparisons confirmed that both effects were highly significant [identity priming: $F 1(1,32)=252.22$, MSE $=307, p<0.001$; $F 2(1,228)=220.00, \mathrm{MSE}=2524, p<0.001$; translation priming: $F 1(1,32)=16.64, \mathrm{MSE}=187, p<0.001 ; F 2(1,228)=7.73$, MSE $=1864, p<0.01 ;$ see Table 4$].$

ANOVAs on the error rates of the word trials revealed a main effect of Relatedness with Greek and English repetition primes leading to $1.9 \%$ more accurate responses to the targets compared to the unrelated primes $[F 1(1,32)=20.65, \mathrm{MSE}=6, p<0.001$; $F 2(1,228)=17.09, \mathrm{MSE}=52, p<0.001]$. The main effect of Prime Language was not significant (both $p s>0.20$ ). However, the interaction between the two factors was significant $[F 1(1,32)=14.67$, $\mathrm{MSE}=7, p<0.001 ; F 2(1,228)=11.42, \mathrm{MSE}=64, p<0.001]$. The subsequent pairwise comparisons showed that participants made $3.5 \%$ less errors when responding to targets preceded by their exact repetition as compared to when they were preceded by unrelated Greek primes [identity priming effect: $F 1(1,32)=29.57, \mathrm{MSE}=8$, $p<0.001 ; \mathrm{F} 2(1,228)=36.43, \mathrm{MSE}=44, p<0.001]$. In contrast, the translation priming effect was not significant (both $p s>0.70$; see Table 5).

Experiment 2 revealed the exact same asymmetric pattern of non-cognate masked translation priming effects found in Experiment 1 with the same test materials but this time with a more proficient group of Greek-English bilinguals. More precisely, we obtained significant but asymmetric masked translation priming effects across the translation directions with Greek-English bilinguals of a medium level of L2 proficiency which were larger with L1 primes and L2 targets (28 ms), than vice versa (14 ms). Again, the significant identity priming and switching cost effects were unaffected by the target language, being highly comparable in Experiments $2 \mathrm{a}$ and $2 \mathrm{~b}$.

Just as in Experiment 1, the masked translation priming asymmetry observed numerically was further corroborated by the significant interaction between Target Language (English, Greek) and Relatedness obtained in a post hoc analysis of the between language priming conditions (translation and unrelated) of sub-experiments $2 \mathrm{a}$ and $2 \mathrm{~b}[F 1(1,32)=3.90, \mathrm{MSE}=524, p=0.5 ; F 2(1,228)=5.08$, MSE $=2920, p<0.05]$. These results, with the exception of the 
Table 5 | Mean lexical decision times (in $\mathrm{ms}, \mathrm{RT}$ ) and error rates (\%E) for word targets in sub-experiments $2 \mathrm{a}$ and $2 \mathrm{~b}$.

\begin{tabular}{|c|c|c|c|c|c|c|c|c|c|c|c|c|c|c|}
\hline \multirow[t]{4}{*}{ Targets } & \multicolumn{8}{|c|}{ Priming Condition } & \multicolumn{6}{|c|}{ Priming Effects } \\
\hline & \multicolumn{4}{|c|}{ English (L2) } & \multicolumn{4}{|c|}{ Greek (L1) } & & & & & & \\
\hline & \multicolumn{2}{|c|}{ Repetition } & \multicolumn{2}{|c|}{ Unrelated } & \multicolumn{2}{|c|}{ Repetition } & \multicolumn{2}{|c|}{ Unrelated } & \multicolumn{2}{|c|}{ Identity } & \multicolumn{2}{|c|}{ Translation } & \multicolumn{2}{|c|}{$\begin{array}{c}\text { Switch } \\
\text { cost }\end{array}$} \\
\hline & RT & $\% \mathrm{E}$ & RT & $\% \mathrm{E}$ & RT & $\% \mathrm{E}$ & RT & $\% \mathbf{E}$ & RT & $\% \mathrm{E}$ & RT & $\% \mathrm{E}$ & RT & $\% \mathrm{E}$ \\
\hline English (L2) & 673 & 5.7 & 736 & 9.0 & 711 & 6.4 & 739 & 8.6 & 63 & 3.3 & 28 & 2.2 & 20 & 0.2 \\
\hline Greek (L1) & 642 & 4.5 & 656 & 4.7 & 596 & 2.3 & 662 & 5.8 & 66 & 3.5 & 14 & 0.2 & 20 & 0.6 \\
\hline
\end{tabular}

Mean reaction times and mean error rates for non-words were 753 ms and 8.8\%, respectively, in Experiment $2 a$ and 707 ms and $5.0 \%$, respectively, in Experiment $2 b$.

significant L2 $\rightarrow$ L1 masked translation effect, offer yet another replication of the masked translation priming asymmetry reported with unbalanced bilinguals. Once more, as shown by the non-significant interaction between Target language and Relatedness for the combined analysis of the within-language priming conditions in the two experiments the masked identity priming effects found for L 2 and L1 targets were symmetrical ( 63 and $66 \mathrm{~ms}$, respectively; ps $>0.61$ ), and the same was the case for the code-switching effects across the two language-switching directions (i.e., non-significant interaction between Target language and Prime language in the combined analysis, both $p s>0.90)$.

Overall, the pattern of masked translation priming effects obtained this far with two groups of bilinguals of different proficiency levels was identical. In the last experiment (Experiment 3) we used once more the same procedure and materials but this time tested an even more proficient group of Greek-English bilinguals; a high proficiency group. Given the absence of a modulation of the effects across the two L2 proficiency levels tested this far, we expected that the same pattern would emerge even with these highly proficient unbalanced bilinguals.

\section{EXPERIMENT 3: HIGH PROFICIENCY GROUP Participants}

Thirty-six native Greek British Council students who were in the process of undertaking the CPE participated in this experiment. At this level of English competence English learners should be able to understand easily virtually all the types of written and spoken English input and to express themselves with precision on all kinds of complex topics. According to the British Council entry test, this group of bilinguals was able to communicate in English effectively and fluently on almost every topic of conversation, using appropriate grammatical and syntactic structures. Participants rated their overall English proficiency with a mean of 7.7 (out of 10; see Table 2).

\section{RESULTS AND DISCUSSION English (L2) targets}

ANOVAs on the word latencies showed a main effect of Prime Language, reflecting a 20 -ms benefit for targets preceded by primes of the same language as compare to when preceded by Greek primes $[F 1(1,32)=45.62, \mathrm{MSE}=304, p<0.001 ; F 2=(1,228)=13.49$, MSE $=6186, p<0.001]$. The main effect of Relatedness was also significant: reaction times were $45 \mathrm{~ms}$ shorter when targets were preceded by English or Greek repetition primes as compared to when the primes were English or Greek unrelated words $[F 1(1,32)=177.62, \mathrm{MSE}=403, p<0.001 ; F 2(1,228)=176.78$, $\mathrm{MSE}=2942, p<0.001]$. Moreover, the interaction between the two factors was significant too, indicating that the Identity and the Translation priming effects differed in magnitude [62 and $28 \mathrm{~ms}$, respectively; $F 1(1,32)=42.86, \mathrm{MSE}=257, p<0.001$; $F 2(1,228)=36.48, \mathrm{MSE}=2883, p<0.001]$. Pairwise comparisons revealed that both the Identity and the Translation priming effects were significant [Identity effect: $F 1(1,32)=181.79, \mathrm{MSE}=382$, $p<0.001 ; F 2(1,228)=183.18, \mathrm{MSE}=2818, p<0.001$; Translation effect: $F 1(1,32)=47.49, \mathrm{MSE}=279, p<0.001 ; F 2(1,228)=36.24$, $\mathrm{MSE}=2507, p<0.001]$.

ANOVAs on the error rates revealed a main effect of Relatedness: participants responded more accurately (2.3\% less errors) to the targets when they were preceded by repetition English and Greek primes as compared to when they were preceded by unrelated English and Greek primes $[F 1(1,32)=26.54, \mathrm{MSE}=7, p<0.001$; $F 2(1,228)=21.80$, MSE $=61, p<0.001]$. The rest of the effects were not significant (all $p s>0.12$ ).

\section{Greek (L1) targets}

ANOVAs on the word latencies revealed a main effect of Prime language. Participants responded $14 \mathrm{~ms}$ faster to targets preceded by Greek primes (repetition and unrelated) as compared to when the targets were preceded by English primes $[F 1(1,32)=25.26, \mathrm{MSE}=295, p<0.001 ; F 2(1,228)=20.17$, $\mathrm{MSE}=2613, p<0.001]$. Moreover, there was a significant main effect of Relatedness. Responses were $34 \mathrm{~ms}$ faster when targets were primed by their repetition (Greek and English) as compared to when they were primed by unrelated Greek or English words $[F 1(1,32)=124.41, \mathrm{MSE}=331, p<0.001 ; F 2(1,32)=157,32$, $\mathrm{MSE}=1803, p<0.001]$. Finally, the interaction between the two factors was also significant $[F 1(1,32)=87.74, \mathrm{MSE}=222$, $p<0.001 ; F 2(1,228)=71.93, \mathrm{MSE}=1803, p<0.001]$. The following pairwise comparisons revealed significant Identity and Translation priming effects [Identity effect: $F 1(1,32)=187.15$, $\mathrm{MSE}=313, p<0.001 ; F 2(1,228)=206.59, \mathrm{MSE}=1949, p<0.001$; Translation effect: $F 1(1,32)=8.37, \mathrm{MSE}=239, p<0.01$; $F 2(1,228)=8.27, \mathrm{MSE}=1709, p<0.01]$ although the Identity priming effect was significantly larger than the Translation effect (57 and $11 \mathrm{~ms}$, respectively), as indicated by the above-described significant interaction. 
ANOVAs on the error rates showed a main effect of Relatedness, with targets primed by their Greek or English repetitions being responded to more accurately ( $1.8 \%$ less errors) than when primed by unrelated Greek and English primes $[F 1(1,32)=22.82, \mathrm{MSE}=5$, $p<0.001 ; F 2(1,228)=15.07, \mathrm{MSE}=49, p<0.001]$. The rest of the effects were not significant (all $p s>0.18$; see Table 6 ).

The results of Experiment 3 ( $3 \mathrm{a}$ and $3 \mathrm{~b}$ ) obtained with highly proficient Greek-English bilinguals exactly replicated those reported with the low and the medium proficiency bilingual groups. Just as in Experiments 1 and 2, we obtained significant identity, code-switching and translation priming effects with both English (Experiment 3a) and Greek (Experiment 3b) targets. Critically, the translation priming effect obtained in the $\mathrm{L} 1 \rightarrow \mathrm{L} 2$ translation (28 ms) was larger than the one obtained in the $\mathrm{L} 2 \rightarrow \mathrm{L} 1$ direction (11 ms), while this was not the case with the identity priming effects and the code-switching effects which were of similar magnitude across languages (identity priming: 62 and $57 \mathrm{~ms}$, in L2 and L1, respectively; switch cost: 20 and 14 ms, with L1 $\rightarrow$ L2 and L2 $\rightarrow$ L1 code-switching, respectively).

The asymmetric pattern of the translation priming effects was further corroborated by the significant interaction between Target Language and Relatedness obtained in a post hoc combined analysis of the reaction times including only the between language priming conditions of Experiments $3 \mathrm{a}$ and $3 \mathrm{~b}$ (Repetition and Unrelated) $[F 1(1,32)=10.60, \mathrm{MSE}=233, p<0.001 ; F 2(1,228)=9.42$, $\mathrm{MSE}=1773, p<0.01]$. On the contrary, this interaction did not reach significance in the within-language priming conditions, indicating that the identity priming effects obtained in L1 and L2 were indeed comparable in magnitude (both $p s>0.19$ ). Likewise, the general combined analyses did not reveal a significant Target language by Prime language interaction, confirming the symmetric pattern of the L1 $\rightarrow \mathrm{L} 2$ and L $\rightarrow$ L1 code-switching masked priming effects $(p s>0.15)$.

Hence, Experiment 3 replicated the non-cognate masked translation priming asymmetry obtained in Experiments 1 and 2 as well as in most of the previous lexical decision studies examining non-cognate masked translation priming effects with unbalanced bilinguals (see Table 1).

\section{COMBINED ANALYSES OF EXPERIMENTS 1-3}

To further compare the apparently identical pattern of the critical masked translation priming effects found across the three levels of L2 proficiency we calculated the net masked translation priming effects in the cross-language priming conditions (Unrelated-Translation) obtained by each group in each translation direction in both the reaction times and the error rates. We conducted ANOVAs including the Level of L2 proficiency as a between subject factor with three levels (low, medium, high) and Translation direction as a within subject factor with two levels (forward, backward). As expected, the only significant effect obtained in both the reaction times and error rates was the main effect of Translation direction (Fs $>3, p s \leq 0.05)$, further corroborating the overall asymmetric pattern of effects. The main effect of Level of L2 proficiency and more importantly, the interaction between the two factors were non-significant (all $p$ s $>0.22$ ).

Despite the seemingly indistinguishable performance of the three groups of bilinguals, post hoc analyses on the reaction times and error rates including the Level of L2 proficiency as a factor revealed that the three groups differed in their overall performance on L2 targets (sub-experiments 1a, 2a, and 3a). These analyses showed a significant main effect of L2 proficiency obtained in both the lexical decision latencies and error rates on the English targets [reaction times: $F 1(2,64)=3.71, \mathrm{MSE}=18848, p<0.05 ; F 2(2,452)=150.01$, $\mathrm{MSE}=3543, p<0.001$; error rates: $F 1(2,64)=21.34, \mathrm{MSE}=0.49$, $p<0.001 ; F 2(2,456)=76.14, \mathrm{MSE}=92, p<0.001]$. Pairwise comparisons revealed that the highly proficient group was faster and more accurate in performing lexical decisions on the English targets as compared to each of the two groups of less proficient bilinguals ( $F s>8, p s<0.01$, with the exception of the high vs. low proficiency reaction times in the $F 1$ analysis: $p=0.09$ ). The pattern of the error rates on the English (L2) targets reflected even closer the L2 proficiency level of each bilingual group, since there were fewer errors the more proficient the bilinguals were, namely a progressive improvement of their performance as a matter of increased proficiency ( $F s>3$, ps $<0.001$, with the exception of the low vs. medium proficiency difference which was marginally significant in the $F 1$ analysis: $p=0.07)$.

\section{GENERAL DISCUSSION}

A review of the existing masked translation priming evidence brought to light the need to empirically examine whether automatic crosslanguage lexico-semantic activation is modulated as a function of increasing levels of L2 proficiency. To this end, we presented three non-cognate masked translation priming lexical decision experiments testing the pattern of effects obtained in the forward and the backward translation direction with three groups of Greek-English

Table 6 | Mean lexical decision times (in ms, RT) and error rates (\%E) for word targets in Experiments 3a and 3b.

\begin{tabular}{|c|c|c|c|c|c|c|c|c|c|c|c|c|c|c|}
\hline \multirow[t]{3}{*}{ Targets } & \multicolumn{8}{|c|}{ Priming Condition } & \multicolumn{6}{|c|}{ Priming Effects } \\
\hline & \multicolumn{4}{|c|}{ English (L2) } & \multicolumn{4}{|c|}{ Greek (L1) } & & & & & & \\
\hline & RT & $\% \mathrm{E}$ & RT & $\% \mathrm{E}$ & RT & $\% \mathrm{E}$ & RT & $\% E$ & RT & $\% \mathrm{E}$ & RT & $\% \mathrm{E}$ & RT & $\% \mathrm{E}$ \\
\hline
\end{tabular}

Mean reaction time and mean error rate for non-words was 747 ms and 5.4\%, respectively, in Experiment $3 a$ and 699 ms and $3.4 \%$, respectively, in Experiment 36 . 
late and unbalanced bilinguals who differed only in their level of English proficiency (relatively low, medium, and high). Our results were straight-forward: although the overall performance in the nondominant language improved as a matter of increased L2 proficiency, the masked translation priming effects obtained were completely unaffected by the proficiency manipulation. In further detail, the word latencies collected revealed that participants were in all cases significantly faster in performing lexical decisions when the targets were preceded by their non-cognate translation as compared to when they were primed by unrelated words of the non-target language. However, and in line with most of the previous evidence obtained with unbalanced bilinguals, this processing benefit was asymmetric depending on the translation direction: it was larger when the primes were the L1 non-cognate translation of the L2 targets, than vice versa. Crucially, the overall pattern of masked translation priming effects resulting from a thoroughly carried out proficiency manipulation confirms that when the bilinguals tested are clearly unbalanced, L2 proficiency does not modulate the non-cognate masked translation priming effects. Finally, significant masked identity effects and codeswitching costs of comparable magnitude were obtained throughout the different levels of L2 proficiency tested, and with both English and Greek targets (see Figure 1, for an overview of the effects).

In the following section each of the different effects obtained starting from the masked identity priming effects, continuing with the code-switching costs and finishing with the critical masked translation priming effects will be discussed in detail. Furthermore, special emphasis will be placed on understanding the relevance of the absence of an effect of L2 proficiency on the automatic coactivation of translation equivalents on the way the bilingual lexicosemantic system could be defined as a bilingual becomes gradually more proficient in the non-dominant language.

\section{MASKED IDENTITY PRIMING EFFECTS}

Contrasting with the asymmetric pattern of masked translation priming effects, the English (L2) and Greek (L1) within-language repetition priming effects observed in the three experiments were of comparable magnitude. This is in line with what has been reported in previous studies with both unbalanced and balanced bilinguals (e.g., Gollan et al., 1997; Perea et al., 2008; Duñabeitia et al., 2010b; Dimitropoulou et al., 2011a). This set of findings shows that masked identity priming effects are unaffected by the difference in the relative exposure to L1 and to L2, even when this difference is rather marked (i.e., low proficient bilinguals). Thus, the symmetric pattern of effects reported so far could be suggesting that identity priming effects in bilingual readers emerge in a functionally language-specific manner, independent from the relative frequency of use of L1 and L2 items. Given the complete prime-target sublexical overlap the observed effects would not be sensitive to the number of times that particular word has been previously encountered. The results from previous bilingual studies examining effects of formal overlap (masked phonological, orthographic, or morphological priming) with native and nonnative speakers further support the idea of the independence of these effects by the nativeness of the participants (Frost et al., 2005; Diependaele et al., 2011; Dimitropoulou et al., 2011b). In fact, given the cross-script nature of our study it could be the case that the script-specific letters of the prime could be boosting the effective activation of the critical words, overwriting any lexical level influence. In line with such a frequency independent account of masked identity priming effects when a different script is involved, Perea et al. (2011) recently found the same amount of masked identity priming for native Arabic speakers and for low proficiency Arabic learners thus suggesting that the relative frequency of use of the test items defined by the amount of exposure to this language, did not affect the results.

\section{MASKED CODE-SWITCHING EFFECTS}

Just like the masked identity priming effects obtained across the three bilingual groups and with both Greek (L1) and English (L2) targets, we also observed remarkably consistent costs associated with a prime-target language switch. Reaction times were slower when the target was preceded by a prime belonging to

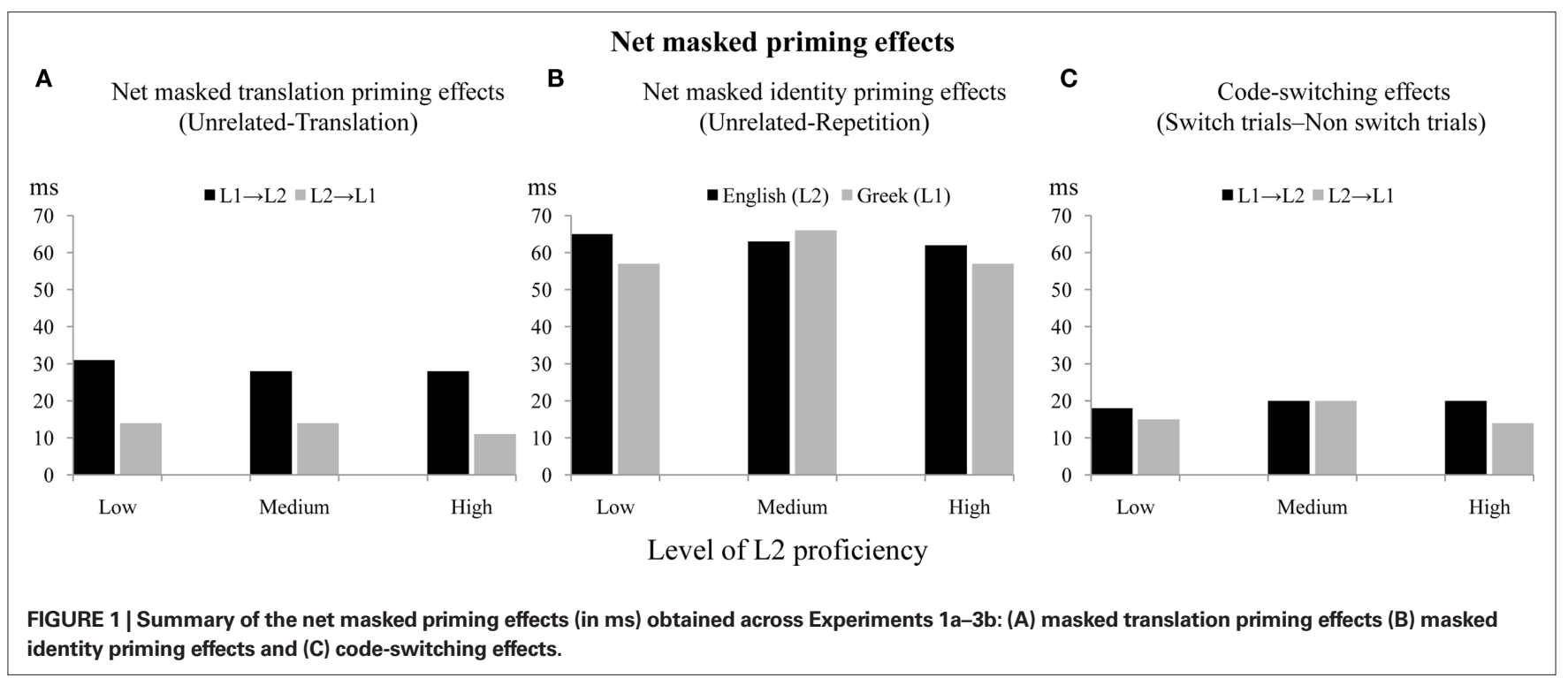


the non-target language ${ }^{2}$. Critically though, these masked priming code-switching effects have not received reliable empirical support since only a handful of masked priming studies have combined within and across-language priming conditions and even less have included prime language as a factor in the analyses reported (Perea et al., 2008; Dimitropoulou et al., 2011a). The reliable switching costs obtained throughout the present series of experiments reveal that language membership is computed in a fast and automatic manner independently from whether the code change has been consciously perceived. This is also confirmed by previous ERP masked priming studies showing that the processing of this information starts as early as $200 \mathrm{~ms}$ after target onset (e.g., Chauncey et al., 2008; Midgley et al., 2009). These findings provide support to the BIA's and BIA-d's postulation that switch cost effects emerge early in the visual word recognition process and could thus be reflecting inhibition of the lexical representations of the non-target language (e.g., Van Heuven et al., 1998; Chauncey et al., 2008; Lam and Dijkstra, 2010), rather than resulting from the operation of a post-lexical language control mechanism as the Inhibitory Control model and partly the BIA+ models propose (e.g., Abutalebi and Green, 2007). Nonetheless, both the BIA and BIA-d models would predict an increase in the top-down inhibition from the L2 language node to the L1 word forms as a matter of increased L2 proficiency (Grainger et al., 2010), which was not reflected in the code-switching costs obtained across the three different levels of English proficiency of our participants.

Moreover, contrary to our behavioral results, in those ERP masked priming studies testing unbalanced bilinguals switch cost effects exhibited a directional asymmetry which was eliminated only with simultaneous and balanced bilinguals (Duñabeitia et al., 2010b; see also Perea, et al., 2008). It should be mentioned though that unlike in these ERP studies, the present code-switching effects could have been greatly affected by the strong visual cue of language membership provided by the script change involved in the primetarget language switch. For bi-scriptal unbalanced bilinguals the influence of script alternation between prime and target could be overwriting any processing asymmetries between their dominant and the non-native language since the script-related information is processed very early in the visual word recognition process (see Hoshino et al., 2010, for cross-script masked translation priming ERP effects). On-going research in our lab is aimed at further testing the influence of the script change in the masked priming code-switching effects.

\section{MASKED TRANSLATION PRIMING EFFECTS}

The asymmetric pattern of masked translation priming effects we obtained across the two translation directions with three groups of unbalanced Greek-English bilinguals is clearly in line with the existing masked translation priming evidence reported in the lexical decision task with unbalanced bilinguals. As previously described, with the exception of one report of symmetric effects with relatively

${ }^{2} \mathrm{~A}$ code-switching cost was also observed in the error rate analysis of Experiment 1. The low proficient Greek-English bilinguals who completed this experiment were less accurate in their lexical decisions to the Greek targets when they were preceded by English primes as compared to the Greek priming conditions. low proficient bilinguals (Duyck and Warlop, 2009), every single study examining forward and backward non-cognate masked translation priming effects with bilinguals with a marked L1 preference has obtained larger effects in the L1 $\rightarrow \mathrm{L} 2$ translation direction (see Table 1). Hence, our results further confirm the existence of the masked translation priming asymmetry with unbalanced bilinguals. With regard to the influence of the level of L2 proficiency on the masked translation priming, the virtually identical priming effects obtained across the three proficiency levels (L1 $\rightarrow$ L2: 31, 28, and $28 \mathrm{~ms}$, in Experiments 1a, 2a, and 3a; L2 $\rightarrow$ L1: 14, 14, and $11 \mathrm{~ms}$, in Experiments 1b, 2b, and 3b) clearly show that when there is a unequivocal language dominance the pattern of masked translation priming effects is completely unaffected by the level of L2 proficiency. More importantly, and in combination with the findings reported with native-like and simultaneous balanced bilinguals (Basnight-Brown and Altarriba, 2007; Duñabeitia et al., 2010a), our results complete the picture of how masked translation priming effects are manifested across the different stages of bilingualism: only native-like bilinguals without a clear language dominance show symmetric masked translation priming effects across the two translation directions.

Interestingly, the otherwise expected asymmetric pattern of masked translation priming effects was manifested in the presence of significant effects in the backward translation direction. This effect was surprisingly present across all groups (even in the least proficient group), thus partially replicating Duyck and Warlop's (2009) findings of significant bi-directional (though symmetric) effects with a group of a comparable L2 proficiency level. Reports of significant L2 $\rightarrow$ L1 non-cognate masked translation priming effects have been so far scarce. Only 8 out of 19 lexical decision experiments testing this translation direction (see Table 1) have reported significant effects, while only two out of them have applied a SOA as short as the one used in our study (i.e., $50 \mathrm{~ms}$ ). Nevertheless, numerically the backward masked translation priming effects we obtained were close to the average 9 ms benefit reported so far in this translation direction, and were in all cases much smaller than those obtained in the forward translation. It could be initially argued that the prime-target script change could have provided a visual cue strong enough to facilitate the processing of the L2 primes even for the less proficient bilinguals. However, significant backward masked translation priming effects previously obtained in the lexical decision task with mono-scriptal unbalanced bilinguals of both high and low L2 proficiency (e.g., Duyck and Warlop, 2009; Schoonbaert et al., 2009, 2010) as well as null backward effects reported under cross-script conditions even with highly proficient bilinguals (Gollan et al., 1997; Jiang, 1999), weaken the validity of this claim. We believe that what led our L2 $\rightarrow \mathrm{L} 1$ effects to be highly significant was a combination of the large statistical power we had (36 participants/group and 58 items/condition) and of the lexical characteristics of the test items. Within the literature, the studies that have found null backward masked translation priming effects have in all cases had narrower sets of data points. Moreover, the fact that the critical non-cognate English translations used were mostly concrete nouns and adjectives of high frequency (a mean word frequency of 86 appearances/million) could have boosted the appearance of the significant L2 $\rightarrow$ L1 translation effects obtained in the present study (see Kroll and Stewart, 1994; Duyck et al., 2008; 
Gollan et al., 2011, for frequency effects in L2 processing). Still, with a closer look at the data gathered in this translation direction it becomes evident that this effect is not the mere result of the ease of lexical access of these familiar L2 words in combination with $¡$ a powerful design. If that were the case one would expect it to be less consistent than the highly significant 15,14 , and $11 \mathrm{~ms}$ found across the three groups of bilinguals, or to be mainly driven by the "deviant" performance of a subgroup of participants. However, the individual data collected revealed that $75 \%$ of the participants responded faster in this translation direction as compared to its corresponding control and that this was consistent within each of the three groups (67-80\% of the participants). Despite the unexpected consistency of the L $2 \rightarrow \mathrm{L} 1$ effect, we consider that the most critical observation regarding these backward masked translation priming effects was that they were in all cases significantly smaller than the L1 $\rightarrow$ L2 effects. This was so across all groups, irrespectively of the gradual improvement of their overall L2 performance as a matter of increased L2 exposure (reaction times and error rates), thus confirming the persistence of the masked translation priming asymmetry with unbalanced bilinguals of different levels of L2 proficiency.

\section{L2 PROFICIENCY AND BILINGUAL LEXICO-SEMANTIC ORGANIZATION}

What do our findings show regarding the way the bilingual lexicosemantic system is organized? First, the significant backward translation priming effects emerging even with the less proficient group, add up to the increasing amount of evidence showing that starting from early in the L2 acquisition process L2 words can directly activate their conceptual representations (e.g., Duyck and Brysbaert, 2004). The fact that this effective L 2 lexico-semantic activation was observed with the low proficiency group under conditions in which no strategic L2 processing was involved (i.e., masked priming), corroborates that from very early on the L2 lexico-semantic access is also highly internalized (see also Duyck and Warlop, 2009; for masked translation priming evidence with low proficient bilinguals in the same line). A similar conclusion is reached with respect to the masked priming code-switching costs obtained with this group: information regarding language membership is automatically computed irrespectively from the level of L2 proficiency. More importantly, the fact that despite the improvement of the participants' L2 performance, the pattern of the observed fast and automatic lexicosemantic effects (identity, switch cost, and non-cognate translation) was practically identical throughout the different L2 proficiency levels shows that the early stages of processing of L2 words take place in an effective way, independently from the amount of exposure to the L2 or from the general performance in that language.

It should be noted though, that this does not mean that the early and automatic stages of L2 processing would be identical across the different types of bilinguals since our findings can be only generalized to unbalanced bilinguals. In fact, an overview of the masked priming literature strongly suggests that there is indeed a critical distinction to be made across bilinguals with respect to the pattern of early and automatic cross-language effects: balanced vs. unbalanced bilingualism. The existence of a clear difference between balanced and unbalanced bilingualism can be clearly deduced considering two critical findings: (i) that the asymmetric pattern of translation and cross-language associative/semantic masked priming effects emerging with unbalanced bilinguals is eliminated with balanced bilinguals (Duyck, 2005; Perea et al., 2008; Schoonbaert et al., 2009; Duñabeitia et al., 2010a) and (ii) that for unbalanced bilinguals cross-language lexico-semantic effects are consistently smaller than within-language ones while for balanced bilinguals these effects are not affected by whether the manipulations involve both languages or just one, (i.e., comparable masked translation and identity priming N400 effects, as well as associative/ semantic effects across languages and within the same language, e.g., Perea et al., 2008; Duñabeitia et al., 2010b). In the light of the present findings it could be concluded that L2 proficiency, strictly defined as the amount of exposure to L2, is not the critical factor influencing these early effects. Hence, in combination with the previous masked priming evidence, the general pattern of our findings supports as more critical the balanced-unbalanced distinction rather than the high-low proficiency distinction.

\section{INTERPRETATION OF THE MASKED TRANSLATION PRIMING EFFECTS BY BILINGUAL MODELS}

Despite the fact that the masked translation priming effects obtained with each of the different groups of Greek-English bilinguals tested were in line with the findings of the vast majority of the previous masked translation lexical decision studies testing unbalanced bilinguals, they only partly confirmed the predictions of the two dominant models of bilingual lexico-semantic organization. As said, the RHM (e.g., Kroll and Stewart, 1994) was the first model to offer an explanation of the asymmetries observed across the two translation directions with unbalanced bilinguals in a series of production studies. To the extent to which the unbalanced bilinguals who participated in our experiments showed in all cases larger forward than backward masked translation priming effects, our findings confirmed the RHM's predictions. However, the absence of any sign of a modulation of the effects by the level of English proficiency of our participants was in clear contrast with the RHM. This model predicted that as the level of L2 proficiency increases the two translation directions should become more comparable to each other, as a result of the increasing ease of direct semantic access for L2 words (see Kroll and de Groot, 1997; Kroll and Tokowicz, 2001; for an adaptation of this prediction on masked translation priming). Clearly our findings did not show any gradual approximation of the two translation directions as a matter of increased L2 proficiency, as the RHM proposed; the masked translation priming asymmetry persisted and the pattern of the effects was identical across the three groups. Additionally, one might have argued that the omnipresent significant L2 $\rightarrow$ L1 effect would have also been unforeseen by the RHM, due to the fact that it reflects the existence of direct semantic access for L2 primes even for the less proficient bilinguals (see Duyck and Warlop, 2009, for discussion). Nevertheless, very recently Kroll et al. (2010) have explicitly stated that the RHM does accept the existence of direct L2 semantic access even at the early stages of L2 acquisition, but that it assumes that during L2 processing, less proficient bilinguals are more likely to engage the activation of the L1 translations (e.g., Sunderman and Kroll, 2006). Hence, and with these latest reformulations, the RHM would effectively account for the persistence of the masked translation priming asymmetry across the L2 proficiency continuum and the significant L2 $\rightarrow \mathrm{L} 1$ masked translation priming 
effects found with unbalanced bilinguals. Critically though, this model would still be unable to predict the absence of any attenuation of the asymmetry.

Analogous limitations are also found when trying to explain our findings within the theoretical framework provided by the computationally implemented BIA (+) models (e.g., Dijkstra and van Heuven, 2002). In unbalanced bilinguals L1 words would be recognized faster than L2 words because they have higher resting levels of activation since they are more frequently encountered. Under this assumption, it is of course expected that with unbalanced bilinguals, like the ones tested throughout our study, an L1 masked prime would pre-activate the shared conceptual node of its L2 translation more effectively than vice versa, thus explaining the directional asymmetry observed with this type of bilingual. Moreover, given that within the BIA framework the lexico-semantic processing differences across the two languages of a bilingual are quantified in a straight-forward manner in terms of frequency of use, the BIA models can also account for the significant backward masked translation priming effects we obtained even with the less proficient group by considering the high lexical frequency of our test items (see above; e.g., Schoonbaert et al., 2010) ${ }^{3}$. However, the BIA models would furthermore predict, that as the level of L2 proficiency and the times a bilingual is faced with L2 words increase the resting levels of activation of L2 lexical items would correspondingly increase and the processing of these $\mathrm{L} 2$ items would gradually become more and more comparable to that of L1 words (i.e., they would be faster recognized). In fact, following the BIA premises Schoonbaert et al. (2010) directly compared the influence of increasing the prime-target SOA to that of increasing the L2 proficiency, since at higher levels of L2 proficiency more processing would be accomplished in a fixed amount of time. Our results did not confirm this prediction, since there was no difference in the pattern of masked translation priming effects obtained across the different levels of L2 proficiency. Even though at the theoretical level the BIA models would have not predicted this pattern of effects, future simulations of these or similar data obtained with bilinguals of different degrees of L2 proficiency would provide a direct test of the validity of the models' predictions (see also Dijkstra and van Heuven, 1998).

The recently proposed developmental version of the BIA models, the BIA-d model, would again fail to predict the exact pattern of our findings (Grainger et al., 2010). This model identifies a "magic moment" in L2 acquisition at which the lexico-semantic system of a late bilingual is shifted from an "RHM-like structure" to a "BIAlike structure." Even though we would be unable to identify if the bilinguals composing our three groups had undergone this shift or not, in either its initial "RHM-like" structure or its later reached "BIA-like" structure the BIA-d model would have predicted that

\footnotetext{
${ }^{3}$ In light of the significant backward masked translation priming effects obtained in their study when presenting the prime for $100 \mathrm{~ms}$ as well as in previous studies using a SOA longer than the common $50 \mathrm{~ms}$ (Duyck and Warlop, 2009; Schoonbaert et al., 2009), Schoonbaert et al. (2010) argued that providing more time to process the prime by increasing the SOA leads to consistent non-cognate masked translation priming effects in the $\mathrm{L} 2 \rightarrow \mathrm{L} 1$ translation direction. However, this proposal is not supported by reports of null backward masked translation priming effects in lexical decision studies applying SOAs as long or even longer (100-250 ms) than the 120-ms one used by Schoonbaert et al. (2010; see Table 1).
}

the masked translation priming effects is modulated as a matter of increased L2 proficiency, reflecting either increased ease of semantic access of L2 words (RHM stages of L2 acquisition) or increased resting levels of activation of L2 words (BIA stages of L2 acquisition) across the three groups. In fact, the authors of the BIA-d also acknowledge that backward non-cognate masked translation priming effects are only expected at the highest levels of L2 proficiency, with balanced bilinguals, thus failing to account for the significant L2 $\rightarrow$ L1 masked translation priming effects we obtained even with the least proficient group. Nevertheless, in all fairness with the model, it should be noted that the BIA-d was explicitly proposed to describe the development of the lexico-semantic organization of mono-scriptal bilinguals and that its computational implementation, the critical test of the model's validity, has not been yet completed.

The only way a theoretical account could predict the absence of a modulation of the non-cognate masked translation priming effects across the three levels of unbalanced bilinguals we tested in the presence of a significant improvement of the overall L2 performance, would be by assuming that for unbalanced bilinguals there is a fundamental L1-L2 processing difference which is unaffected by the level of L2 proficiency. Jiang and Forster (2001) put forward such a proposal termed as the Episodic L2 Hypothesis, motivated by their findings of significant backward masked translation priming effects in the episodic recognition task but not in the lexical decision task. According to this account L2 words are represented only in the episodic (non-lexical) memory module in association with their L1 translation, while L1 words are both episodically and lexically represented (Forster, 1985). For most L2 learners, the establishment of L2 lexical representations is not achieved because L2 words are usually learnt after the semantic system has been already established. Following Jiang and Forster's (2001) rationale, given that the lexical decision task taps on lexical representations, the benefit of priming an L1 target by its L2 translation would be smaller than the benefit obtained when the order of prime and target language is reversed. Since the briefly presented L2 masked prime is only episodically represented it would fail to activate the lexical L1 representation as required in the lexical decision task, but it would effectively activate its trace in the episodic memory. Although Jiang and Forster's (2001) episodic L2 proposal accounts at present only for a subset of the bilingual masked priming findings (e.g., if L2 items lack of the lexical representations needed to perform lexical decisions how do then backward masked translation priming effects emerge in the lexical decision task?), it critically assumes that the L2 episodic representations would persist across the different L2 proficiency stages. As the authors state "it is possible that once an L2 word is represented in non-lexical memory, it will always remain there" (p. 49). Hence, by presupposing the persistence of the episodic memory traces of L2 words across the proficiency span the Episodic L2 Hypothesis would predict that masked priming effects should be unaffected by L2 proficiency, in line with our findings.

\section{THE POTENTIAL INFLUENCE OF AGE OF L2 ACQUISITION ON AUTOMATIC LEXICO-SEMANTIC CROSS-LANGUAGE ACTIVATION}

If the critical distinction in the pattern of non-cognate masked translation priming effects reported throughout the lexical decision studies across the multiple groups tested is found between balanced 
and unbalanced bilinguals and if this distinction is not grounded on L2 proficiency differences, then which is the variable triggering the shift from the asymmetric to the symmetric pattern? According to some of the latest theoretical proposals as well as recent empirical evidence this critical factor could be the age of L2 acquisition (L2 AoA, hereafter), based on which bilinguals would be grouped into early (or simultaneous) and late bilinguals. Jiang and Forster (2001) in the initial formulation of the Episodic L2 Hypothesis, proposed that the lexical/episodic distinction between $\mathrm{L} 1$ and $\mathrm{L} 2$ words stands mostly for bilinguals who have acquired their L2 much later than their L1, as it is the case with our participants. Due to maturational reasons, the acquisition of the dominant and the non-dominant languages in late L2 learners might rely on different mechanisms (potentially the lexical and the episodic memory systems), thus leading to asymmetric effects. In contrast, early learners acquiring their L1 and L2 in a relatively parallel way may have established lexical representations for both languages, in which case no asymmetry is expected in the pattern of masked translation priming effects obtained in the lexical decision task. Likewise, L2 AoA is also assigned such a fundamental part in the way L2 items are represented by Devlex-II, a computational model of bilingual lexical development and interaction (Zhao and Li, 2006, 2010). Devlex-II is an unsupervised connectionist network that does bilingual lexicon learning based on Hebbian Learning principles. Although the model does predict the expansion of the L2 lexicon with extensive training (i.e., increased proficiency), it proposes that it is the L2 AoA what mainly defines the functional properties of the L2 lexicon. As opposed to the well-defined lexica of simultaneous or early L2 bilinguals, the L2 lexicon of late bilinguals would be poorly defined and "parasitically" related to L1 representations. (Zhao and Li, 2010). In fact, even the BIA-d model (Grainger et al., 2010) emphasizes the importance of L2 AoA in shaping the bilingual lexicon by stating that their developmental hypothesis would exclusively hold for late L2 learners. Likewise, recent studies point to a critical involvement of L2 AoA in the representational L1-L2 balance and its impact on semantic processing. Grossi et al. (2010) found that only in late bilinguals performing a semantic categorization task in their L2 the hemispheric lateralization of the N1 ERP component, the earliest component thought to reflect linguistic processing, was highly correlated to the $\mathrm{L} 1$ pattern of $\mathrm{N} 1$ lateralization. This pattern suggests that for late and not for early bilinguals the L2 lexical organization is delimited by the existing L1 organization. Furthermore, in an fMRI translation priming study, Isel et al. (2010) found different neural patterns of cross-language repetition enhancement for early and late bilinguals performing a semantic categorization task. Hence, from both a theoretical and an empirical perspective, it could be inferred that L2 AoA could be critically involved in the pattern of cross-language lexico-semantic activation. If L2 words are acquired simultaneously or in close temporal proximity to the acquisition of the L1 items they will develop stronger semantic connections with them and will be represented in a way similar to that of L1 items. This would in turn, be manifested as an attenuation of the L1-L2 processing asymmetries.

What is even more noteworthy is that when grouping the bilinguals who have participated in the existing masked translation priming lexical decision studies in early and late L2 learners the picture obtained is remarkably consistent with the proposal that
L2 AoA could be indeed driving the overall pattern of masked translation priming effects. On the one hand, the studies reporting the typical asymmetric masked translation priming pattern have tested late bilinguals who had started acquiring their L2 after early childhood (see Table 1). On the other hand, the studies presenting symmetric bi-directional effects have tested either simultaneous or early bilinguals (Basnight-Brown and Altarriba, 2007; Duñabeitia et al., 2010a,b $)^{4}$. Similar to what was the case with L2 proficiency, the potential influence of the L2 AoA on masked translation priming has not been investigated in isolation from other confounded variables. The most important limitation in this respect lays in the fact that all the studies examining masked translation priming effects have tested either late unbalanced or simultaneous/early native-like bilinguals. The present study is the first masked translation priming study to intentionally tear these two factors apart by examining bilinguals of different levels of L2 proficiency who were matched in their L2 AoA (see Table 2). The finding that with late unbalanced bilinguals the L2 proficiency manipulation alone did not affect the masked translation priming asymmetry points to the need to focus future research on L2 AoA as a potential factor driving the differences observed across balanced and early vs. unbalanced and late bilinguals in masked translation priming, suggesting that this factor which has been typically neglected in word recognition studies (favoring proficiency manipulations) might significantly alter the L2 word processing mechanisms of bilingual readers.

In more general terms, how would a simultaneous/early vs. late L2 AoA distinction affect the bilingual lexico-semantic organization? In our view this distinction would first affect the process followed to acquire the L2, and consequently the way L1 and L2 words become activated with respect to each other. Considering the tapping of the masked priming paradigm on non-strategic early processing, we will develop our rationale mostly based on evidence gathered using this paradigm while taking into account previous benchmark effects of the bilingual literature. In line with what has been already established, any theoretical proposal on bilingual lexico-semantic processing would have to assume (i) that performance in each language would improve as a matter of increased exposure $^{5}$, (ii) that starting from the sublexical level, activation would proceed in a parallel way across the two languages, with fast and automatic cross-language interactions taking place, and (iii) that $\mathrm{L} 2$ direct lexico-semantic access would be achieved even by late and low proficient bilinguals. Critically, in this framework L2 AoA would not affect the ease of access of each specific lexical item but the functional segregation of the two languages. As previously mentioned, late bilinguals acquire their second language after both the semantic system and the L1 lexico-semantic mappings have been established. The temporal separation of the L1 and the L2 systems would be reflected as a functional segregation of L1 and L2 words in a way that language-specific lexico-semantic activation would be

${ }^{4}$ The only study whose results do not agree with this age of acquisition distinction is the Duyck and Warlop (2009) study reporting symmetric effects with late low proficient Dutch-French bilinguals (mean L2 AoA: 11 years). However, as mentioned this pattern could have been due to a lack of statistical power.

${ }^{5}$ The way in which increased exposure would affect the overall processing of each language would depend on the ortho-phonological relationship of the words of the two languages (e.g., script, proportion of cognates, interlingual homographs, etc.) and on the relative frequency of each specific lexical item (e.g., Gollan et al., 2011). 
more effective as compared to cross-language activation. Evidence in support of this proposal comes from studies showing comparable within-language masked priming lexico-semantic effects in native speakers and in less proficient late bilinguals when performing a pure L2 task (e.g., form, morphological, or identity priming; Frost et al., 2005; Diependaele et al., 2011; Dimitropoulou et al., 2011a) and from the fact that with late bilinguals masked translation priming effects have been in all cases found to be significantly smaller than masked identity priming effects (e.g., Midgley et al., 2009; Dimitropoulou et al., 2011a; the present study). Moreover, in most cases, late bilinguals rely on the already existing L1 translations to acquire the new L2 words. This would be reflected as a larger initial reliance on the activation of the L1 translation when recognizing and especially when producing L2 items (e.g., Elston-Güttler et al., 2005; Sunderman and Kroll, 2006).

In contrast, for simultaneous or early bilinguals L2 words would be acquired while the organization of the semantic system and of the L1 lexicon is not yet completed and would thus be represented with a less marked language tag (i.e., they would be functionally indistinguishable from L1 items), leading to comparable cross-language, and within-language effects. In support of this assumption, Perea et al. (2008) found comparable cross-language and within-language masked associative/semantic priming effects with early BasqueSpanish bilinguals, while Duñabeitia et al. (2010b) found symmetric N400 masked identity and masked translation priming effects with a different group of simultaneous bilinguals. Furthermore, given that early bilinguals usually acquire the L 2 in a natural context without making reference to the $\mathrm{L} 1$, the co-activation of translation equivalents would mostly result from top-down feedback caused by their semantic overlap and less by association at the lexical level. This is reflected in the pattern of masked translation priming ERP effects reported so far. Critically, only the studies testing late bilinguals have found, in addition to the N400 effects, significant non-cognate masked translation priming effects in the N250 time-window (e.g., Midgley et al., 2009), while Duñabeitia et al. (2010b) testing simultaneous bilinguals have only reported N400 effects, suggesting that with these bilinguals the co-activation of non-cognate translations is

\section{REFERENCES}

Abutalebi, J., and Green, D. W. (2007). Bilingual language production: the neurocognition of language representation and control. J. Neurolinguistics 20, 242-275.

Altarriba, J., and Basnight-Brown, D. M. (2007). Methodological considerations in performing semantic and translation-priming experiments across languages. Behav. Res. Methods Instrum. Comput. 39, 1-18.

Alvarez, R. P., Holcomb, P. J., and Grainger, J. (2003). Accessing word meaning in two languages: an event-related brain potential study of beginning bilinguals. Brain Lang. 87, 290-304.

Baayen, R. H., Piepenbrock, R., and van Rijn, H. (1995). The CELEX Lexical Database. Release 2 [CD-ROM]. Philadelphia: Linguistic Data Consortium, University of Pennsylvania.
Basnight-Brown, D. M., and Altarriba, J. (2007). Differences in semantic and translation priming across languages: the role of language direction and language dominance. Mem. Cognit. 35, 953-965.

Chauncey, K., Grainger, J., and Holcomb, P. J. (2008). Code-switching effects in bilingual word recognition: a masked priming study with ERPs. Brain Lang. 105, 161-174.

Chee, M. W. L., Hon, N., Ling Lee, H., and Siong Soon, C. (2001). Relative language proficiency modulates BOLD signal change when bilinguals perform semantic judgments. Neuroimage 13, 1155-1163.

Chen, H. C., and Leung, Y. S. (1989). Patterns of lexical processing in a nonnative language. J. Exp. Psychol. Learn. Mem. Cogn. 15, 316-325.

Christoffels, I. K., de Groot, A. M. B., and Kroll, J. F. (2006). Memory and

initiated later and is exclusively dependent on their semantic overlap. Obviously, there are numerous predictions to be tested about how L2 AoA could affect the automatic processing of L1 and L2 words and about how AoA would interact with L2 proficiency. With regard to the masked translation priming effect, an essential test of this account would be to explore (i) whether the symmetric masked translation priming pattern obtained with early balanced bilinguals would persist with late balanced bilinguals and (ii) whether early but unbalanced bilinguals would exhibit the masked translation priming asymmetry consistently found with late unbalanced bilinguals.

\section{CONCLUSION}

By providing a thorough review of the growing body of masked translation priming studies, the present study further highlights the value of this paradigm to unravel early and automatic cross-language lexico-semantic effects. Moreover, we empirically addressed the issue of whether these effects are modulated by the degree of competence of bilinguals in their non-dominant language. Our results showed that the automatic L1 and L2 lexico-semantic activation patterns of unbalanced bilinguals are intrinsically asymmetric and that they are not modulated by increased exposure to the second language. Given that the most cited models of bilingual processing would clearly predict that the asymmetry would be soothed as a matter of increased proficiency, we believe that our findings invite future research to try to identify the conditions under which the L1-L2 representational imbalance characterizing the largest part of bilinguals is eliminated.

\section{ACKNOWLEDGMENTS}

This research has been partially supported by Grants CONSOLIDERINGENIO 2010 (CSD2008-00048) and (PSI 2009-08889) from the Spanish Ministry of Science and Innovation. Maria Dimitropoulou was the recipient of a post-graduate grant from the Government of the Canary Islands (BOC 241, 02/12/2008). The authors thank Cliff Parry and the British Council in Athens for their collaboration in the recruitment of participants. Special thanks are also due to Tamar Gollan for her insightful comments.

language skills in simultaneous interpreting: expertise and language proficiency. J. Mem. Lang. 54, 324-345.

Coltheart, M., Davelaar, E., Jonasson, J. T., and Besner, D. (1977). "Access to the internal lexicon," in Attention and Performance VI ed. S. Dornic (New York: Academic Press), 535-555.

Comesaña, M., Perea, M., Piñeiro, A., and Fraga, I. (2009). Vocabulary teaching strategies and conceptual representations of words in L2 in children: evidence with novice beginners. J. Exp. Child. Psychol. 104, 22-33.

Costa, A., Santesteban, M., and Ivanova, I. (2006). How do highly proficient bilinguals control their lexicalization process? Inhibitory and languagespecific selection mechanisms are both functional. J. Exp. Psychol. Learn. Mem. Cogn. 32, 1057-1074.

Davis, C., Sánchez-Casas, R., GarcíaAlbea, J. E., Guasch, M., Molero, M., and Ferré, P. (2010). Masked translation priming: varying language experience and word type with Spanish-English bilinguals. Biling. (Camb. Engl.) 13, 137-155.

Davis, C. J. (2005). N-watch: a program for deriving neighborhood size and other psycholinguistic statistics. Behav. Res. Methods 37, 65-70.

De Groot, A. M. B., and Nas, G. L. (1991). Lexical representation of cognates and noncognates in compound bilinguals. J. Mem. Lang. 30, 90-123.

De Groot, A. M. B., and Poot, R. (1997). Word translation at three levels of proficiency in a second language: the ubiquitous involvement of conceptua memory. Lang. Learn. 47, 215-264.

Diependaele, K., Duñabeitia, J.A., Morris, J., and Keulers, E. (2011). Fast morphological effects in first and second language word recognition. J. Mem. Lang. 64, 344-358. 
Dijkstra, A. F. J., and van Heuven, W. J. B. (1998). "The BIA-model and bilingual word recognition," in Localist Connectionist Approaches to Human Cognition, eds J. Grainger and A. M. Jacobs (Mahwah, NJ: Erlbaum), 189-225.

Dijkstra, T. (2007)."The multilingual lexicon," in Handbook of Psycholinguistics, ed. M. G. Gaskell (Oxford: Oxford University Press), 251-265.

Dijkstra, T., and van Heuven, W. J. B. (2002). The architecture of the bilingual word recognition system: from identification to decision. Biling. (Camb. Engl.) 5, 175-197.

Dimitropoulou, M., Duñabeitia, J. A., and Carreiras, M. (2011a). Masked translation priming effects with low proficient bilinguals. Mem. Cognit. 39, 260-275.

Dimitropoulou, M., Duñabeitia, J. A., and Carreiras, M. (2011b). Phonology by itself: masked phonological priming effects with and without orthographic overlap. J. Cogn. Psychol. 23, 185.

Duñabeitia, J.A., Perea, M., and Carreiras, M. (2010a). Masked translation priming effects with highly proficient simultaneous bilinguals. Exp. Psychol. 57, 98-107.

Duñabeitia, J. A., Dimitropoulou, M., Uribe-Etxebarria, O., Laka, I., and Carreiras, M. (2010b). Electrophysiological correlates of the masked translation priming effect with highly proficient simultaneous bilinguals. Brain Res. 1359, 142-154.

Duyck, W. (2005). Translation and associative priming with cross-lingual pseudohomophones: evidence for nonselective phonological activation in bilinguals. J. Exp. Psychol. Learn. Mem. Cogn. 31, 1340-1359.

Duyck, W., and Brysbaert, M. (2004). Forward and backward translation in balanced and unbalanced bilinguals requires conceptual mediation: the magnitude effect in number translation. J. Exp. Psychol. Hum. Percept. Perform. 30, 889-906.

Duyck, W., Diependaele, K., Drieghe, D., and Brysbaert, M. (2004). The size of the cross-lingual masked phonological priming effect does not depend on second language proficiency. Exp. Psychol. 51, 116-124.

Duyck, W., Vanderelst, D., Desmet, T., and Hartsuiker, R. J. (2008). The frequency effect in second-language visual word recognition. Psychon. Bull. Rev. 15, 850-855.

Duyck, W., and Warlop, N. (2009). Translation priming between the native language and a second language: new evidence from DutchFrench bilinguals. Exp. Psychol. 56, 173-179.
Elston-Güttler, K. E., Paulmann, S., and Kotz, S. A. (2005). Who's in control? Proficiency and L1 influence on L2 processing. J. Cogn. Neurosci. 17, 1593-1610.

Favreau, M., and Segalowitz, N. S. (1983). Automatic and controlled processes in the first- and second-language reading of fluent bilinguals. Mem. Cognit. 11, 565-574.

Ferré, P., Sánchez-Casas, R., and Guasch, M. (2006). Can a horse be a donkey? Semantic and form interference effects in translation recognition in early and late proficient and non-proficient Spanish-Catalan bilinguals. Lang. Learn. 56, 571-608.

Finkbeiner, M. (2005). “Task-dependent L2-L1 translation priming: an investigation of the separate memory systems account," in Proceedings of the 4th International Symposium on Bilingualism, eds J. Cohen, K. T. McAlister, K. Rolstad, and J. MacSwan (Somerville, MA: Cascadilla Press), 741-750.

Finkbeiner, M., Forster, K. I., Nicol, J., and Nakumura, K. (2004). The role of polysemy in masked semantic and translation priming. J. Mem. Lang. 51, 1-22.

Forster, K. I. (1985). Lexical acquisition and the modular lexicon. Lang. Cogn. Process. 1, 87-108.

Forster, K. I., and Davis, C. (1984). Repetition priming and frequency attenuation in lexical access. J. Exp. Psychol. Learn. Mem. Cogn. 10, 680-698.

Forster, K. I., and Forster, J. C. (2003). DMDX: a windows display program with millisecond accuracy. Behav. Res. Methods Instrum. Comput. 35, 116-124.

Forster, K. I., and Jiang, N. (2001). “The nature of the bilingual lexicon: experiments with the masked priming paradigm," in One Mind, Two Languages: Bilingual Language Processing, ed. J. L. Nicol (Malden, MA: Blackwell Publishing), 72-83.

French, R. M., and Jacquet, M. (2004). Understanding bilingual memory: models and data. Trends Cogn. Sci. (Regul. Ed.) 8, 87-93.

Frost, R., Kugler, T., Deutsch, A., and Forster, K. I. (2005). Ortho- graphic structure versus morphological structure: principles of lexical organization in a given language. $J$. Exp. Psychol. Learn. Mem. Cogn. 31, 1293-1326.

Gollan, T. H., Forster, K. I., and Frost, R. (1997). Translation priming with different scripts: masked priming with cognates and noncognates in HebrewEnglish bilinguals. J. Exp. Psychol. Learn. Mem. Cogn. 23, 1122-1139.

Gollan, T. H., Slattery, T. J., Goldenberg, D., van Assche, E., Duyck, W., and
Rayner, K. (2011). Frequency drives lexical access in reading but not in speaking: the frequency-lag hypothesis. J. Exp. Psychol. Gen. 140, 186-209.

Grainger, J., and Frenck-Mestre, C. (1998). Masked translation priming in bilinguals. Lang. Cogn. Process. 13, 601-623.

Grainger, J., Midgley, K., and Holcomb, P. J. (2010). "Re-thinking the bilingual interactive-activation model from a developmental perspective (BIAd)," in Language Acquisition Across Linguistic and Cognitive Systems, eds M. Kail and M. Hickmann (New York: John Benjamins), 267-284.

Grossi, G., Savill, N., Thomas, E., and Thierry, G. (2010). Posterior N1 asymmetry to English and Welsh words in early and late English-Welsh bilinguals. Biol. Psychol. 85, 124-133.

Hoshino, N., Midgley, K. J., Holcomb, P. J., and Grainger, J. (2010). An ERP investigation of masked cross-script translation priming. Brain Res. 1344 159-172.

Isel, F., Baumgaertner,A., Thrän, J., Meisel, J. M., and Büchel, C. (2010). Neural circuitry of the bilingual mental lexicon: effect of age of second language acquisition. Brain Cogn. 72, 169-180.

Jiang, N. (1999). Testing processing explanations for the asymmetry in masked cross-language priming. Biling. (Camb. Engl.) 2, 59-75.

Jiang, N., and Forster, K. I. (2001). Crosslanguage priming asymmetries in lexical decision and episodic recognition. J. Mem. Lang. 44, 32-51.

Kim, J., and Davis, C. (2003). Task effects in masked cross-script translation and phonological priming. J. Mem. Lang. 49, 484-499.

Kinoshita, S., and Lupker, S. J. (eds). (2003). Masked Priming: State of the Art. Hove: Psychology Press.

Kroll, J. F., and de Groot, A. M. B. (1997). "Lexical and conceptual memory in the bilingual: mapping form to meaning in two languages," in Tutorials in Bilingualism: Psycholinguistic Perspectives, eds A. M. B. de Groot and J.F. Kroll (Mahwah, NJ: Erlbaum), 169-199.

Kroll, J. F., Michael, E., Tokowicz, N., and Dufour, R. (2002). The development of lexical fluency in a second language. Second Lang. Res. 18, 137-171.

Kroll,J.F., and Stewart,E. (1994). Category interference in translation and picture naming: evidence for asymmetric connections between bilingual memory representations. J. Mem. Lang. 33 , 149-174.

Kroll, J. F., and Tokowicz, N. (2001)."The development of conceptual representation for words in a second language," in One Mind, Two Languages: Bilingual Language Processing, ed. J. L. Nicol
(Malden, MA: Blackwell Publishers), 49-71.

Kroll, J. F., and Tokowicz, N. (2005). "Models of bilingual representation and processing: looking back and to the future," in Handbook of Bilingualism: Psycholinguistic Approaches, eds J. F. Kroll and A. M. B. De Groot (New York: Oxford University Press), 531-553.

Kroll, J. F., van Hell, J. G., Tokowicz, N., and Green, D. W. (2010). The revised hierarchical model: a critical review and assessment. Biling. (Camb. Engl.) 13, 373-381.

Ktori, M., van Heuven, W. J. B., and Pitchford, N. J. (2008). GreekLex: a lexical database of modern greek. Behav. Res. Methods 40, 773-783.

Lam, K., and Dijkstra, T. (2010). Modeling code-interactions in bilingual word recognition: recent empirical studies and simulations with BIA+. Int. J. Biling. Educ. Biling. 13, 487-503.

Leonard, M. K., Torres, C., Travis, K. E., Brown, T. T., Hagler, D. J. Jr., Dale, A. M., Elman, J. L., and Halgren, E. (2011). Language proficiency modulates the recruitment of non-classical language áreas in bilinguals. PLoS ONE 6, e18240. doi: 10.1371/journal. pone. 0018240

Marian, V., Blumenfeld, H. K., and Kaushanskaya, M. (2007). The language experience and proficiency questionnaire (LEAP-Q): assessing language profiles in bilinguals and multilinguals. J. Speech Lang. Hear. Res. 50, 940-967.

McClelland, J. L., and Rumelhart, D. E. (1981). An interactive activation model of context effects in letter perception: part 1. An account of basic findings. Psychol. Rev. 88, 375-407.

Midgley, K. J., Holcomb, P. J., and Grainger, J. (2009). Masked repetition and translation priming in second language learners: a window on the time-course of form and meaning activation using ERPs. Psychophysiology 46, 551-565.

Nakamura, K., Kouider, S., Makuuchi, M., Kuroki, C., Hanajima, R., Yoshikazu Ugawa, Y., and Ogawa, S. (2010). Neural control of cross-language asymmetry in the bilingual brain Cereb. Cortex 20, 2244-2251.

Perea, M., Abu Mallouh, R., García-Orza, J., and Carreiras, M. (2011). Masked priming effects are modulated by expertise in the script. Q. J. Exp. Psychol. 64, 902-919.

Perea, M., Duñabeitia, J.A., and Carreiras, M. (2008). Masked associative/semantic and identity priming effects across languages with highly proficient bilinguals. J. Mem. Lang. 58, 916-930.

Perea, M., and Rosa, E. (2000). Repetition and form priming interact with 
neighborhood density at a short stimulus-onset asynchrony. Psychon. Bull. Rev. 7, 668-677.

Pollatsek, A., and Well, A. (1995). On the use of counterbalanced designs in cognitive research: a suggestion for a better and more powerful analysis. J. Exp. Psychol. Learn. Mem. Cogn. 21, 785-794.

Sánchez-Casas, R. M., Davis, C. W., and García-Albea, J. E. (1992). Bilingual lexical processing: exploring the cognate/non-cognate distinction. Eur. J. Cogn. Psychol. 4, 293-310.

Schoonbaert, S., Duyck, W., Brysbaert, M., and Hartsuiker, R. J. (2009). Semantic and translation priming from a first language to a second and back: making sense of the findings. Mem. Cognit. 37, 569-586.

Schoonbaert, S., Holcomb, P. J., Grainger, J., and Hartsuiker, R. J. (2010). Testing asymmetries in noncognate translation priming: evidence from RTs and ERPs. Psychophysiology 48, 74-81.
Sunderman, G., and Kroll, J. F. (2006). First language activation during second language lexical processing: an investigation of lexical form, meaning, and grammatical class. Stud. Second Lang. Acquis. 28, 387-422.

Talamas, A., Kroll, J. F., and Dufour, R. (1999). From form to meaning: stages in the acquisition of second language vocabulary. Biling. (Camb. Engl.) 2, $45-58$.

Thierry, G., and Wu, Y. J. (2007). Brain potentials reveal unconscious translation during foreign-language comprehension. Proc. Natl. Acad. Sci. U.S.A. 104, 12530-12535.

Van Heuven, W. J. B., Dijkstra, A. F. J., and Grainger, J. (1998). Orthographic neighborhood effects in bilingual word recognition. J. Mem. Lang. 39, 458-483.

Van Heuven, W. J. B., and Dijkstra, T. (2010). Language comprehension in the bilingual brain: fMRI and ERP support for psycholinguistic models. Brain Res. Rev. 64, 104-122.
Voga, M., and Grainger, J. (2007). Cognate status and cross-script translation priming. Mem. Cognit. 35, 938-952.

Wang, X., and Forster, K. I. (2010). Masked translation priming with semantic categorization: testing the sense model. Biling. (Camb. Engl.) 13, 327-340.

Williams, J. N. (1994). The relationship between word meanings in the first and second language: evidence for a common, but restricted, semantic code. Eur. J. Cogn. Psychol. 6, 195-220.

Zhao, X., and Li, P. (2006). "A self-organizing connectionist model of bilingual lexical development," in Proceedings of CogSci, 2006, Vancouver.

Zhao, X., and Li, P. (2010). Bilingual lexical interactions in an unsupervised neural network model. Int. J. Biling. Educ. Biling. 13 505-524.

Conflict of Interest Statement: The authors declare that the research was conducted in the absence of any commercial or financial relationships that could be construed as a potential conflict of interest.

Received: 18 February 2011; paperpending published: 13 May 2011; accepted: 25 July 2011; published online: 15 August 2011. Citation: Dimitropoulou M, Duñabeitia JA and Carreiras M (2011) Two words, one meaning: evidence of automatic coactivation of translation equivalents. Front. Psychology 2:188. doi: 10.3389/ fpsyg.2011.00188

This article was submitted to Frontiers in Language Sciences, a specialty of Frontiers in Psychology.

Copyright (C) 2011 Dimitropoulou, Duñabeitia and Carreiras. This is an openaccess article subject to a non-exclusive license between the authors and Frontiers Media SA, which permits use, distribution and reproduction in other forums, provided the original authors and source are credited and other Frontiers conditions are complied with. 